\title{
Air Pollution with Particulate Matter and Mutagens: Relevance of Asian Dust to Mutagenicity of Airborne Particles in Japan
}

\author{
Tetsushi Watanabe ${ }^{1,15}$, Tomohiro Hasei ${ }^{1}$, Osamu Kokunai ${ }^{1}$, Souleymane Coulibaly ${ }^{1}$, \\ Sachi Nishimura1, Moe Fukasawa1, Ryohei Takahashi', Yasuko Mori ${ }^{1}$, Kosuke Fujita ${ }^{1}$, \\ Yuri Yoshihara', Yumi Miyake1, Akane Kishi' ${ }^{1}$, Motoki Matsui ${ }^{1}$, Fumikazu Ikemori'2, \\ Kunihiro Funasaka ${ }^{3}$, Akira Toriba ${ }^{4}$, Kazuichi Hayakawa ${ }^{4}$, Kei-ichi Arashidani ${ }^{5}$, Yohei Inaba ${ }^{6}$, \\ Nobuyuki Sera7, Yuya Deguchi ${ }^{8}$, Tetsurou Seiyama9, Takako Yamaguchi ${ }^{10}$, \\ Masanari Watanabe ${ }^{11}$, Naoko Honda ${ }^{1,12}$, Keiji Wakabayashi ${ }^{1,13}$ and Yukari Totsuka ${ }^{14}$ \\ ${ }^{1}$ Kyoto Pharmaceutical University, Kyoto, Japan \\ ${ }^{2}$ Nagoya City Institute of Environmental Science, Aichi, Japan \\ ${ }^{3}$ Osaka City Institute of Public Health and Environmental Science, Osaka, Japan \\ ${ }^{4}$ Kanazawa University, Ishikawa, Japan \\ 5University of Occupational and Environmental Health, Fukuoka, Japan \\ ${ }^{6}$ National Institute of Public Health, Saitama, Japan \\ ${ }^{7}$ Fukuoka Institute of Health Environmental Science, Fukuoka, Japan \\ ${ }^{8}$ Nagasaki International University, Nagasaki, Japan \\ ${ }^{9}$ Tottori Prefectural Institute of Public Health and Environmental Science, Tottori, Japan \\ ${ }^{10}$ Kobe Gakuin University, Hyogo, Japan \\ ${ }^{11}$ Tottori University, Tottori, Japan \\ ${ }^{12}$ Sonoda Women's University, Hyogo, Japan \\ ${ }^{13}$ University of Shizuoka, Shizuoka, Japan \\ ${ }^{14}$ National Cancer Center, Tokyo, Japan
}

Received April 15, 2014; Revised May 12, 2014; Accepted May 14, 2014 J-STAGE Advance published date: May 21, 2014

To reveal the contamination levels of ambient air with particulate matter and mutagens in Japan and the influence of their long-range transport from the Asian continent, we collected airborne particles at 10 sites, from rural sites to metropolitan areas, in central and western areas of Japan for a year, from July 2008 to June 2009. The fluctuation patterns and levels of airborne particle concentration were similar among the 10 sites, and remarkable increases of the concentrations were seen on a few sampling dates, including March 16 and 17, 2009. Most airborne particles collected at the 10 sites showed mutagenicity toward Salmonella typhimurium YG1024 without a mammalian metabolic system (S9 $\mathrm{mix}$ ) in the Ames test. The mutagenicity levels were quite different among the sampling sites, and the levels seemed to be dependent on the extent of urbanization and industrialization of the subject areas. At Yurihama, a rural site on the west coast of Japan, the mutagenicity level of airborne particles was low, but the particles collected on March 16 and 17, 2009, showed relatively high mutagenicity, >40 revertants $/ \mathrm{m}^{3}$, in YG1024 without S9 mix. Airborne particles collected on March 16 and 17, 2009, at most sites showed relatively high or high mutagenicity, $>80$ revertants $/ \mathrm{m}^{3}$, in YG1024 without S9 mix. High coefficients of correlation were found between the concentration and mutagenicity of airborne particles collected in spring, from March to May, for many sites. The results of back trajectory analysis indicated that air masses for March 16 and 17, 2009, had moved from the Asian continent to Japan. The arrival of Asian dust in central and western areas of Japan on those days was reported by the Japan Meteorological Agency. These results suggest that the arrival of mutagens accompanied by Asian dust could be evidently found at Yurihama on March 2009.

Key words: ambient air, suspended particle, Japan, Asian dust, Ames test

${ }^{15}$ Correspondence to: Tetsushi Watanabe, Kyoto Pharmaceutical University, 1 Misasagi-Shichonocho, Yamashina-ku, Kyoto 607-8412, Japan. Tel: +81-75-595-4650, Fax: +81-75-595-4769, E-mail: watanabe@mb.kyoto-phu.ac.jp doi: org/10.3123/jemsge.2014.013 


\section{Introduction}

Many epidemiological studies have demonstrated that ambient air pollution is associated with mortality from lung cancer, respiratory diseases, and so forth (1-6). The International Agency for Research on Cancer (IARC) classified outdoor air pollution and particulate matter, a major component of outdoor air pollution, as "carcinogenic to humans (Group 1)" (7). Some particulates occur naturally from volcanoes, forest fires, and so forth. Human activities, such as the burning of fossil fuels in motor vehicles and power plants, also generate particulate matter and emit it into the air. Mutagenic/ carcinogenic substances, for example, polycyclic aromatic hydrocarbons (PAHs), are also formed by incomplete combustion of organic material such as fossil fuel and emitted into the air from various anthropogenic sources (8-11). Therefore, the pollution level of ambient air in terms of particulate matter and mutagenic/carcinogenic substances is thought to depend on the extent of urbanization and industrialization of the subject area. On the other hand, it is well known that the longrange transport of air pollutants occurs (12-16). For instance, Katayama et al. (12) examined the source-receptor relationship for sulfur in East Asia in December 1995, using a regional chemical transport model coupled with a Regional Atmospheric Modeling System, and estimated that the total contribution of transborder pollution from the Asian continent to sulfur deposition in Japan was almost $75 \%$. This transborder pollution was thought to be caused by the seasonal wind (winter monsoon), which blow northeast to Japan. Moreover, Asian dust (yellow dust or yellow sand) affects much of East Asia, including Japan, sporadically during the spring. Asian dust originates in arid areas in northwestern China and southern Mongolia, such as the Takla Makan and Gobi deserts, and is then carried eastward by Westerlies and seasonal winds and passes over China, Korea, and Japan. In 2009, the total energy consumption in China reached 3.1 billion tons of coal equivalents (17). China has overtaken the United States to become the world's largest energy user. With the rapid growth of the domestic economy and urbanization in China, the emissions of air pollutants from coal combustion, industrial production, and transport have been increasing at an unprecedented rate over the last decade (18). Therefore, mutagenic/carcinogenic substances originating from these anthropogenic sources may reach other countries by long-range transport via the winter monsoon and Westerlies like Asian dust. However, there are few reports on the long-range transport of mutagenic/ carcinogenic substances from the Asian continent to Japan.

In the present study, we collected airborne particles at 10 sites, from rural sites to metropolitan areas, in Japan over a year, from July 2008 to June 2009, and assayed their mutagenicity by the Salmonella Ames test to reveal the contamination levels of the ambient air in Japan with airborne particles and mutagens and the influence of their long-range transport from the Asian continent. The size distributions of particles and 10 PAHs, classified as priority pollutants by the United States Environmental Protection Agency, were also examined for airborne particles collected in Kyoto from January 17 to 21, 2011 (without an Asian dust event), and from May 1 to 6, 2011 (with an Asian dust event). The movements of air masses from which we collected airborne particles were simulated by back trajectory analysis. The influence of the long-range transport of airborne particles and mutagens was also discussed.

\section{Material and Methods}

Reagents: Quartz filters were purchased from Pall Life Sciences (Port Washington, NY, USA). Benzo[a]pyrene (BaP, CAS 50-32-8), benzo[b]fluoranthene (BbF, CAS 205-99-2), benzo[ $k$ ]fluoranthene (BkF, CAS 207-08-9), and indeno[1,2,3-cd]pyrene (IcdP, CAS 193-39-5) were purchased from Wako Pure Chemical Industries, Ltd. (Osaka, Japan). Benz $[a]$ anthracene (BaA, CAS 56-55-3) and dibenz $[a, h]$ anthracene (DahA, CAS 53-70-3) were purchased from Tokyo Chemical Industry Co., Ltd. (Tokyo, Japan). Fluoranthene (FR, CAS 206-44-0) and pyrene (PY, CAS 129-00-0) were purchased from Nacalai Tesque Inc. (Kyoto, Japan). Chrysene (CHR, 218-01-9) and benzo[ghi]perylene (BghiP, CAS 191-24-2) were purchased from SigmaAldrich Co. LLC (St. Louis, MO, USA). All other chemicals and reagents were of analytical grade.

Sampling of airborne particles and sample preparation: Total suspended particles were collected at 10 sites (Fig. 1), namely, Sasebo City (Nagasaki Prefecture), Dazaifu City (Fukuoka Prefecture), Kitakyushu City (Fukuoka Prefecture), Yurihama Town (Tottori Prefecture), Kobe City (Hyogo Prefecture), Osaka City (Osaka Prefecture), Kyoto City (Kyoto Prefecture), Nagoya City (Aichi Prefecture), Kanazawa City (Ishikawa Prefecture), and Wako City (Saitama Prefecture), located across a wide area of the center and west of Japan. Total suspended particles are thought to be airborne particles with diameters less than $100 \mu \mathrm{m}$ (19). The characteristics of the sampling sites are shown in Table 1. Kobe, Osaka, and Kyoto constitute the Keihanshin metropolitan area, the second largest metropolitan area in Japan. Nagoya is a core city of the Chukyo metropolitan area, the third largest metropolitan area. Wako is located in the Kanto metropolitan area, the largest metropolitan area. Kitakyushu is a core city of the Kitakyushu-Fukuoka metropolitan area, the fourth largest metropolitan area in Japan. Dazaifu is located $16 \mathrm{~km}$ southeast of Fukuoka City, another core city of the Kitakyushu-Fukuoka metropolitan area. 


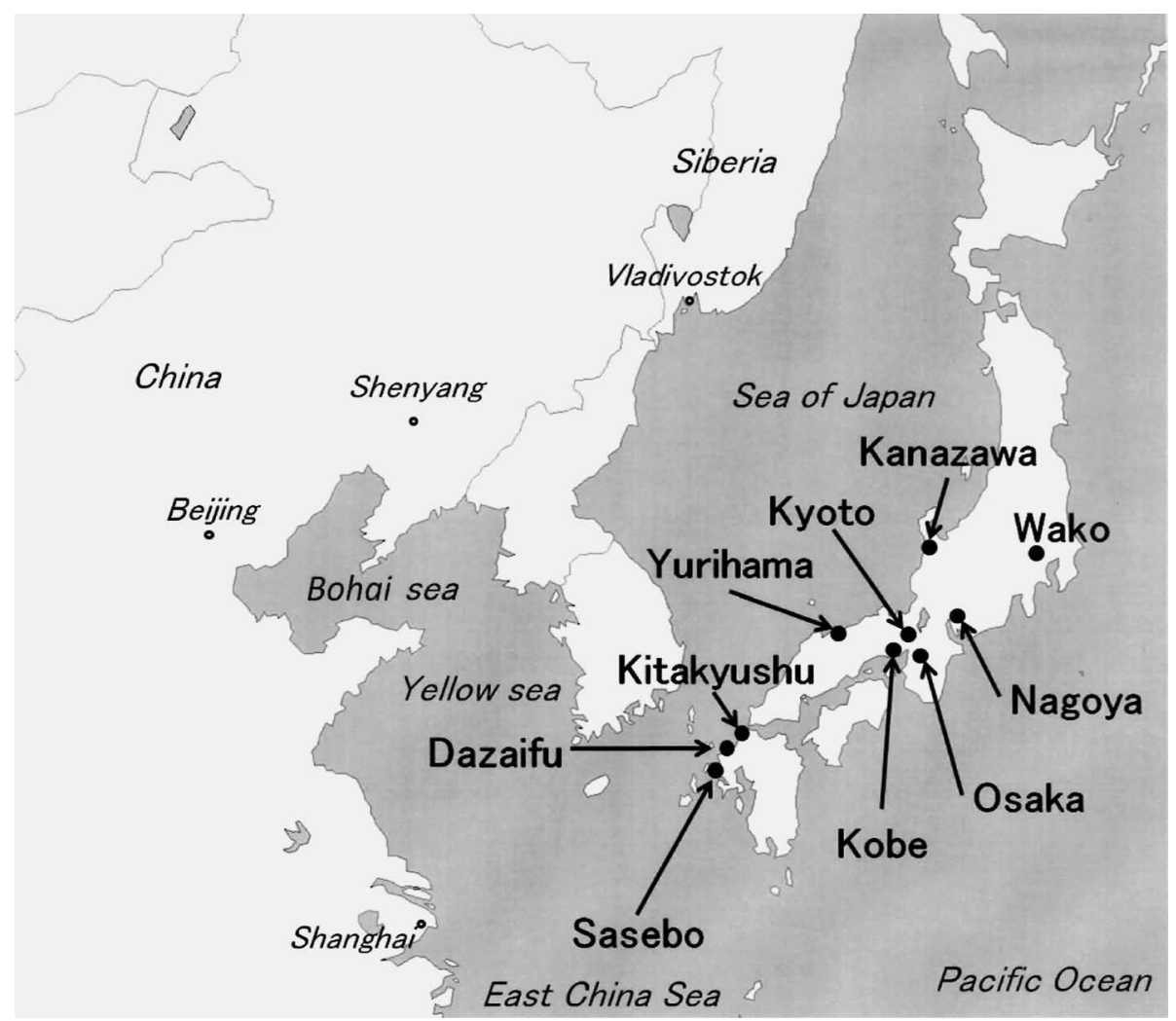

Fig. 1. Sampling sites of airborne particles.

Table 1. Characteristics of sampling sites

\begin{tabular}{|c|c|c|c|c|}
\hline Sampling site & Population & $\begin{array}{l}\text { Population density } \\
\qquad\left(/ \mathrm{km}^{2}\right)\end{array}$ & Metropolitan area & $\begin{array}{l}\text { Characteristic of sampling site } \\
\text { (Major industry) }\end{array}$ \\
\hline Sasebo & 258,430 & 606 & - & $\begin{array}{l}\text { Countryside } 10 \mathrm{~km} \text { away from harbor } \\
\text { (Shipbuilding) }\end{array}$ \\
\hline Dazaifu & 71,200 & 2,410 & Kitakyushu-Fukuoka & $\begin{array}{l}\text { Countryside } 16 \mathrm{~km} \text { away from Fukuoka commercial area } \\
\text { (Sightseeing, farming) }\end{array}$ \\
\hline Kitakyushu & 971,931 & 1,990 & Kitakyushu-Fukuoka & $\begin{array}{l}\text { Residential area near industrial area } \\
\text { (Heavy industry, sightseeing) }\end{array}$ \\
\hline Yurihama & 16,884 & 217 & - & $\begin{array}{l}\text { Countryside far from any metropolitan area } \\
\text { (Sightseeing, farming) }\end{array}$ \\
\hline Kobe & $1,542,230$ & 2,790 & Keihanshin & $\begin{array}{l}\text { Harbor near commercial area } \\
\text { (Heavy industry, shipbuilding, sightseeing) }\end{array}$ \\
\hline Osaka & $2,678,549$ & 12,010 & Keihanshin & $\begin{array}{l}\text { Commercial area } \\
\text { (Heavy industry, sightseeing) }\end{array}$ \\
\hline Kyoto & $1,473,069$ & 1,780 & Keihanshin & $\begin{array}{l}\text { Residential area } \\
\text { (Sightseeing, traditional industry, farming) }\end{array}$ \\
\hline Nagoya & $2,268,423$ & 6,950 & Chukyo & $\begin{array}{l}\text { Industrial area } \\
\text { (Heavy industry) }\end{array}$ \\
\hline Kanazawa & 463,679 & 991 & - & $\begin{array}{l}\text { Moutainside } 6 \mathrm{~km} \text { away from commercial area } \\
\text { (Sightseeing, traditional industry, farming, fishing) }\end{array}$ \\
\hline Wako & 81,315 & 7,370 & Kanto & $\begin{array}{l}\text { Rural area next to Tokyo Prefecture } \\
\text { (Heavy industry) }\end{array}$ \\
\hline
\end{tabular}

Therefore, Dazaifu was thought to be influenced by Fukuoka. Populations of Sasebo and Kanazawa are about 258,000 and 464,000, respectively, and are considered as medium-sized cities. Neither of them belongs to any metropolitan area. The sampling site in Sasebo is lo- cated near a harbor, and that in Kanazawa is $6 \mathrm{~km}$ away from the commercial area and surrounded by mountains. Yurihama is in the countryside. Sampling sites in Yurihama and Kanazawa have few large emission sources of air pollutants. 

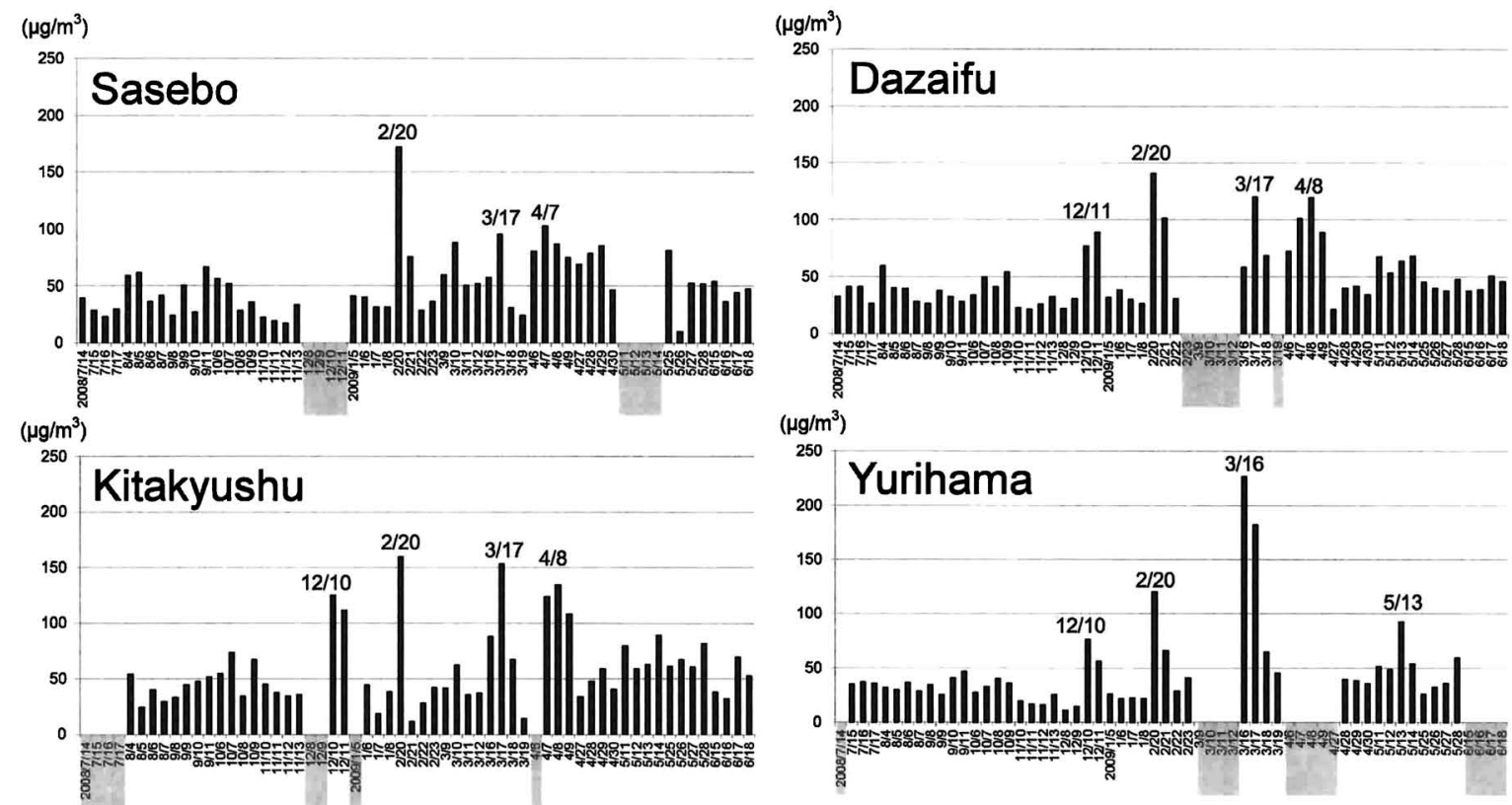

$\left(\mu \mathrm{g} / \mathrm{m}^{3}\right)$

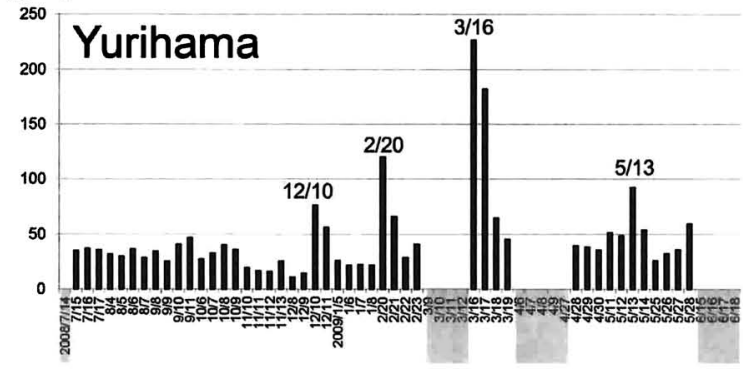

$\left(\mu \mathrm{g} / \mathrm{m}^{3}\right)$

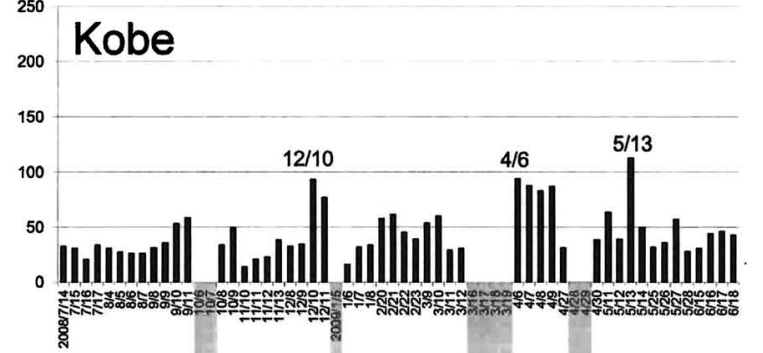

$\left(\mu \mathrm{g} / \mathrm{m}^{3}\right)$

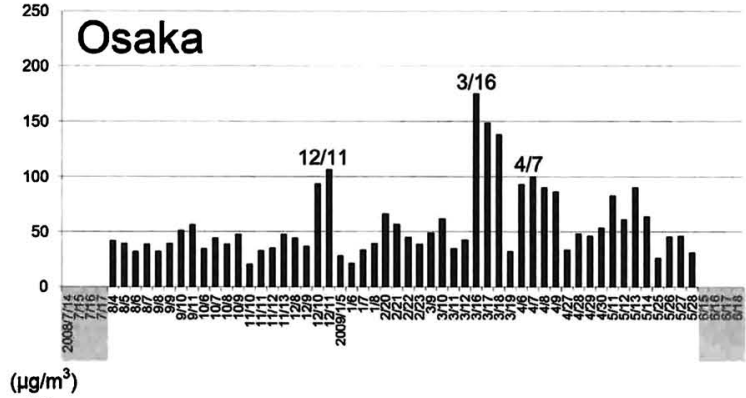

$\left(\mu \mathrm{g} / \mathrm{m}^{3}\right)$
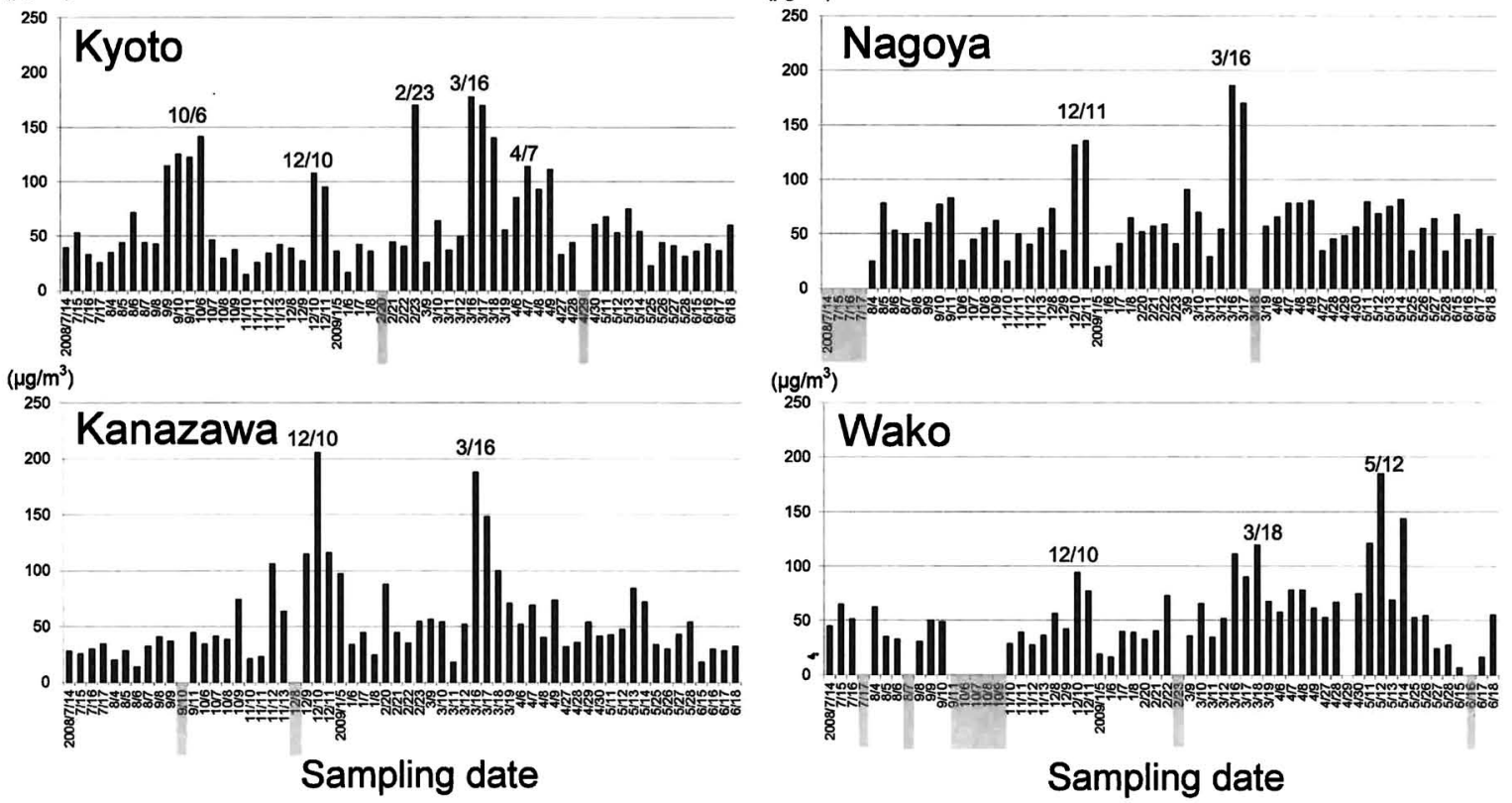

Fig. 2. Concentration of airborne particles collected at the 10 sites from July 2008 to June 2009. Sampling dates when collection was not performed are shaded. 
The sampling periods were as follows: July 14-17, August 4-7, September 8-11, October 6-9, November 10-13, and December 8-11 in 2008; and January 5-8, February 20-23, March 9-12, 16-19, April 6-9, 27-30, May 11-14, 25-28, and June 15-18 in 2009. In this study, seasons were defined as follows: spring months are March, April, and May; summer months are June, July, and August; autumn months are September, October, and November; and winter months are December, January, and February.

The sampling of airborne particles started at about 10 AM (Japan Standard Time, JST) and finished at about 10 AM the next day at every sampling site. The airborne particles were collected on quartz filters at a flow rate of $700-1400 \mathrm{~L} / \mathrm{min}$ with high-volume air samplers (Shibata Scientific Technology Ltd., Soka, Japan, or Kimoto Electric Co. Ltd., Osaka, Japan) for about 24 h. Total air volume was in the range of $900-1600 \mathrm{~m}^{3}$. The filters were weighted before and after sampling after being humidified at 50\% relative humidity with sodium hydrogen sulfate solution at $20^{\circ} \mathrm{C}$. To calculate the concentration of airborne particles, the weight of airborne particles collected on a filter was divided by the volume of the air that had passed through the filter.

Extracts of airborne particles were prepared as described previously (20). Forty percent of the filter (corresponding to $360-640 \mathrm{~m}^{3}$ air) was cut into small pieces and extracted with $100 \mathrm{~mL}$ of methanol using an ultrasonic apparatus for $20 \mathrm{~min}$. All airborne particle extracts were filtered through No. $5 \mathrm{C}$ filter papers (Advantec Toyo, Tokyo, Japan) and $75 \mathrm{ml}$ of filtrate was evaporated to dryness.

Mutagenic assay: The extracts of airborne particles were dissolved in dimethyl sulfoxide and assayed by the preincubation method (21) using Salmonella typhimurium YG1024 (22) and YG1029 (22) with and without S9 mix. YG1024 and YG1029 were kindly pro- vided by Dr. Nohmi from the National Institute of Health. YG1024 and YG1029 are $O$-acetyltrasferaseoverproducing derivatives of Salmonella typhimurium TA98 and TA100, respectively, and are sensitive to mutagens that require metabolic activation by $O$ acetyltrasferase, such as nitroaromatic compounds. Nitroaromatic compounds, such as 1-nitropyrene, are representative environmental mutagens. YG1024 and YG1029 were used in this study because of the sensitivity to these environmental mutagens. The S9 mix contained $0.05 \mathrm{~mL}$ of $\mathrm{S} 9$, prepared from livers of male Sprague-Dawley rats treated with phenobarbital and $\beta$ naphthoflavone, in a total volume of $0.5 \mathrm{~mL}$. The mutagenic potencies of samples were calculated from linear portions of the dose-response curves obtained with three or four doses and duplicated plates at each dose. The

Table 3. Concentrations of airborne particles at the 10 sites in the four seasons and annually

\begin{tabular}{|c|c|c|c|c|c|c|}
\hline \multirow{2}{*}{ Period } & \multicolumn{6}{|c|}{ Concentration of airborne particles $\left(\mu \mathrm{g} / \mathrm{m}^{3}\right)$} \\
\hline & Sasebo & Dazaifu & Kitakyushu & Yurihama & Kobe & \\
\hline Summer & $42 \pm 12$ & $40 \pm 9$ & $42 \pm 15$ & $33 \pm 3$ & $33 \pm 8$ & \\
\hline Autumn & $37 \pm 16$ & $34 \pm 10$ & $46 \pm 13$ & $30 \pm 10$ & $36 \pm 15$ & \\
\hline Winter & $57 \pm 49$ & $56 \pm 40$ & $64 \pm 53$ & $42 \pm 32$ & $48 \pm 23$ & \\
\hline Spring & $64 \pm 25$ & $63 \pm 28$ & $70 \pm 34$ & $69 \pm 58$ & $56 \pm 26$ & \\
\hline Year & $51 \pm 28$ & $50 \pm 27$ & $59 \pm 34$ & $46 \pm 40$ & $45 \pm 22$ & \\
\hline \multirow{2}{*}{ Period } & \multicolumn{6}{|c|}{ Concentration of airborne particles $\left(\mu \mathrm{g} / \mathrm{m}^{3}\right)$} \\
\hline & Osaka & Kyoto & Nagoya & Kanazawa & Wako & 10 sites \\
\hline Summer & $38 \pm 4$ & $43 \pm 13$ & $52 \pm 16$ & $26 \pm 6$ & $41 \pm 20$ & $39 \pm 13$ \\
\hline Autumn & $40 \pm 10$ & $64 \pm 46$ & $52 \pm 18$ & $47 \pm 25$ & $37 \pm 9$ & $42 \pm 22$ \\
\hline Winter & $51 \pm 26$ & $59 \pm 46$ & $61 \pm 38$ & $78 \pm 54$ & $48 \pm 24$ & $56 \pm 39$ \\
\hline Spring & $70 \pm 39$ & $71 \pm 44$ & $71 \pm 38$ & $62 \pm 38$ & $75 \pm 39$ & $67 \pm 37$ \\
\hline Year & $56 \pm 32$ & $62 \pm 41$ & $62 \pm 32$ & $55 \pm 39$ & $58 \pm 34$ & $55 \pm 34$ \\
\hline
\end{tabular}

Numbers express mean values \pm standard deviation.

Table 2. The total sampling days and dates of high airborne particle concentration $\left(>100 \mu \mathrm{g} / \mathrm{m}^{3}\right)$

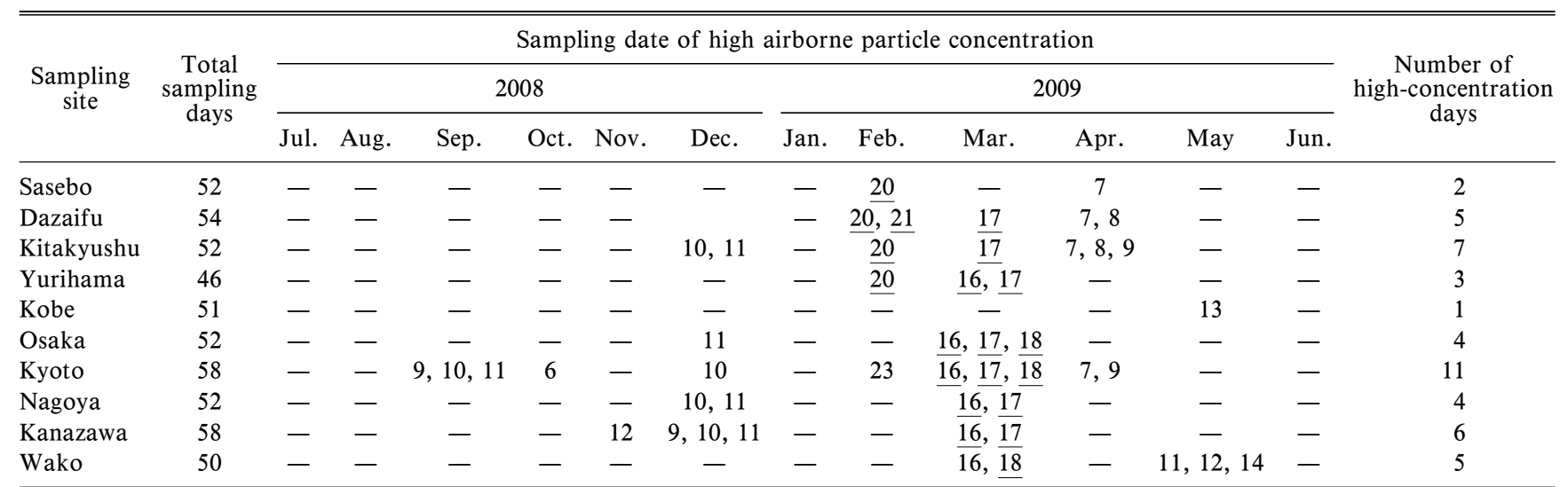

The dates when Asian dust arrived as reported by the Japan Meteorological Agency (25) are underlined. 
Sasebo

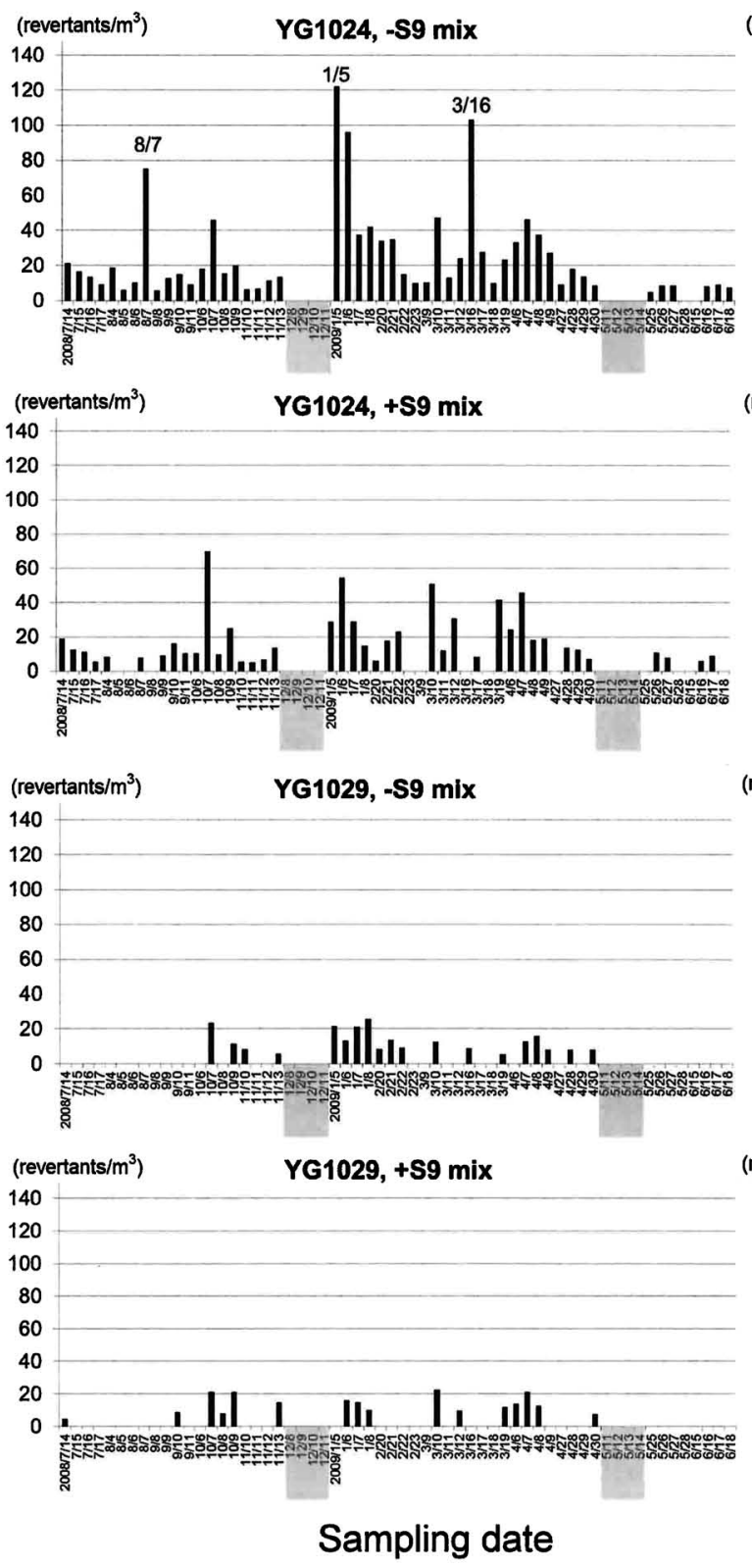

\section{Dazaifu}
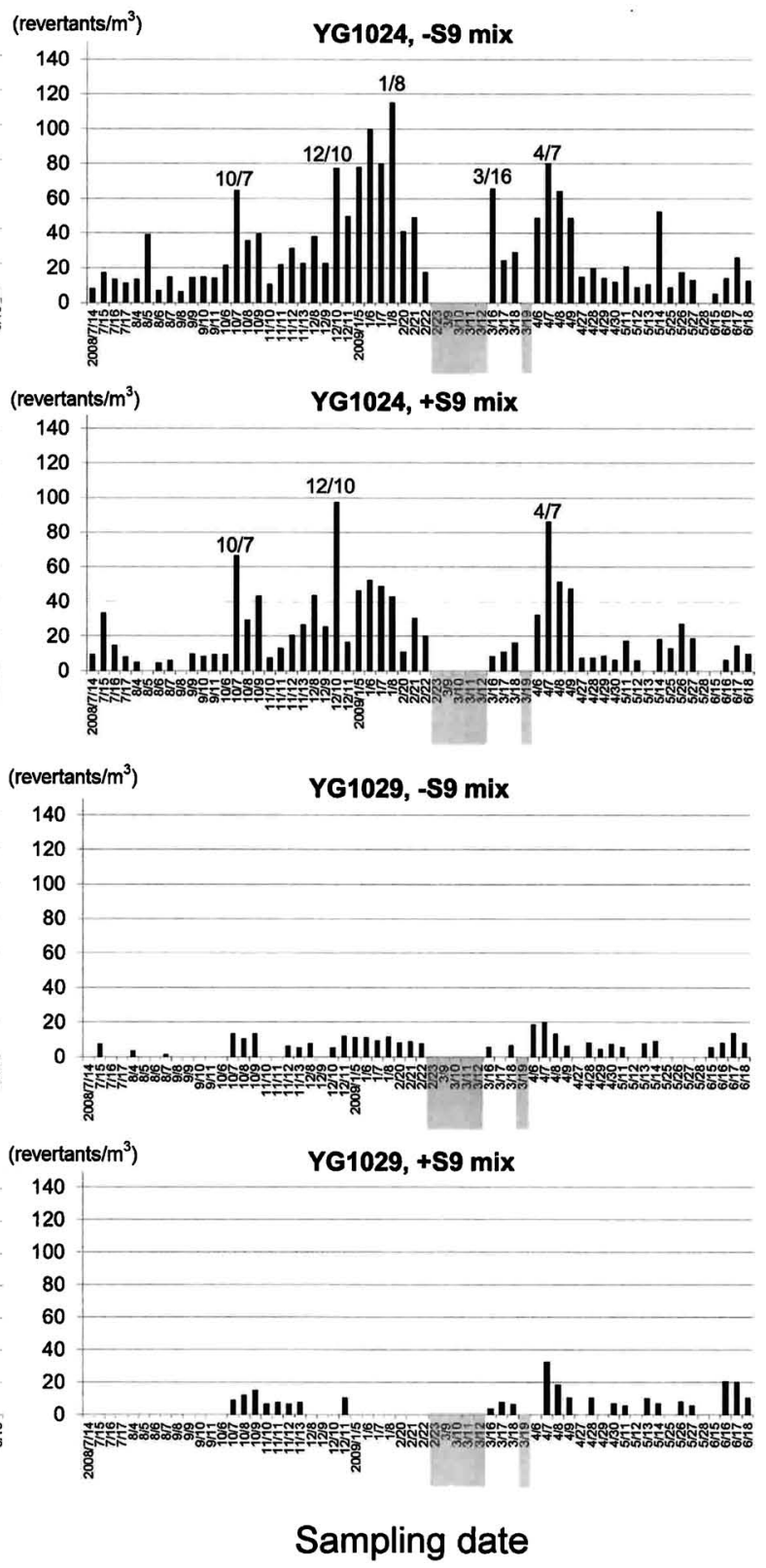

Fig. 3. Mutagenicities of airborne particles collected at the 10 sites from July 2008 to June 2009. Sampling dates when collection was not performed are shaded. The mean values of negative control were as follows: 43 revertants/plate (YG1024, - S9 mix), 133 revertants/plate (YG1024, +S9 mix), 160 revertants/plate (YG1029, - S9 mix), 165 revertants/plate (YG1029, + S9 mix). The mean values of positive control were as follows: 353 revertants/plate (YG1024, -S9 mix, 1-nitrpyrene $0.01 \mu \mathrm{g} /$ plate), 473 revertants/plate (YG1024, + S9 mix, acetylaminofluorene 0.02 $\mu \mathrm{g} /$ plate), 584 revertants/plate (YG1029, - S9 mix, furylfuramide $0.02 \mu \mathrm{g} /$ plate), 1163 revertants/plate (YG1029, $+\mathrm{S} 9 \mathrm{mix}, \mathrm{BaP} 2 \mu \mathrm{g} / \mathrm{plate}$ ).

slope of each dose-response curve was adopted as the mutagenic potency. When the samples induced twofold increases over the average of spontaneous revertants and showed well-behaved concentration-response patterns, the samples were judged as positive. As positive controls, $\mathrm{BaP}$ and 2-acetylaminofluorene were used in the presence of S9 mix, and 1-nitropyrene and furylfuramide were utilized in the absence of S9 mix
Sampling of size-fractionated airborne particles and analysis of PAHs: Size-fractionated airborne particles, namely, <1.1, 1.1-2.0, 2.0-3.3, 3.3-7.0, and $>7.0 \mu \mathrm{m}$, were collected in Kyoto on quartz filters at a flow rate of $566 \mathrm{~L} / \mathrm{min}$ with an Andersen-type highvolume air sampler (Shibata Scientific Technology Ltd., Soka, Japan) from January 17 to 21, 2011 (without an Asian dust event), and from May 1 to 6, 2011 (with an 

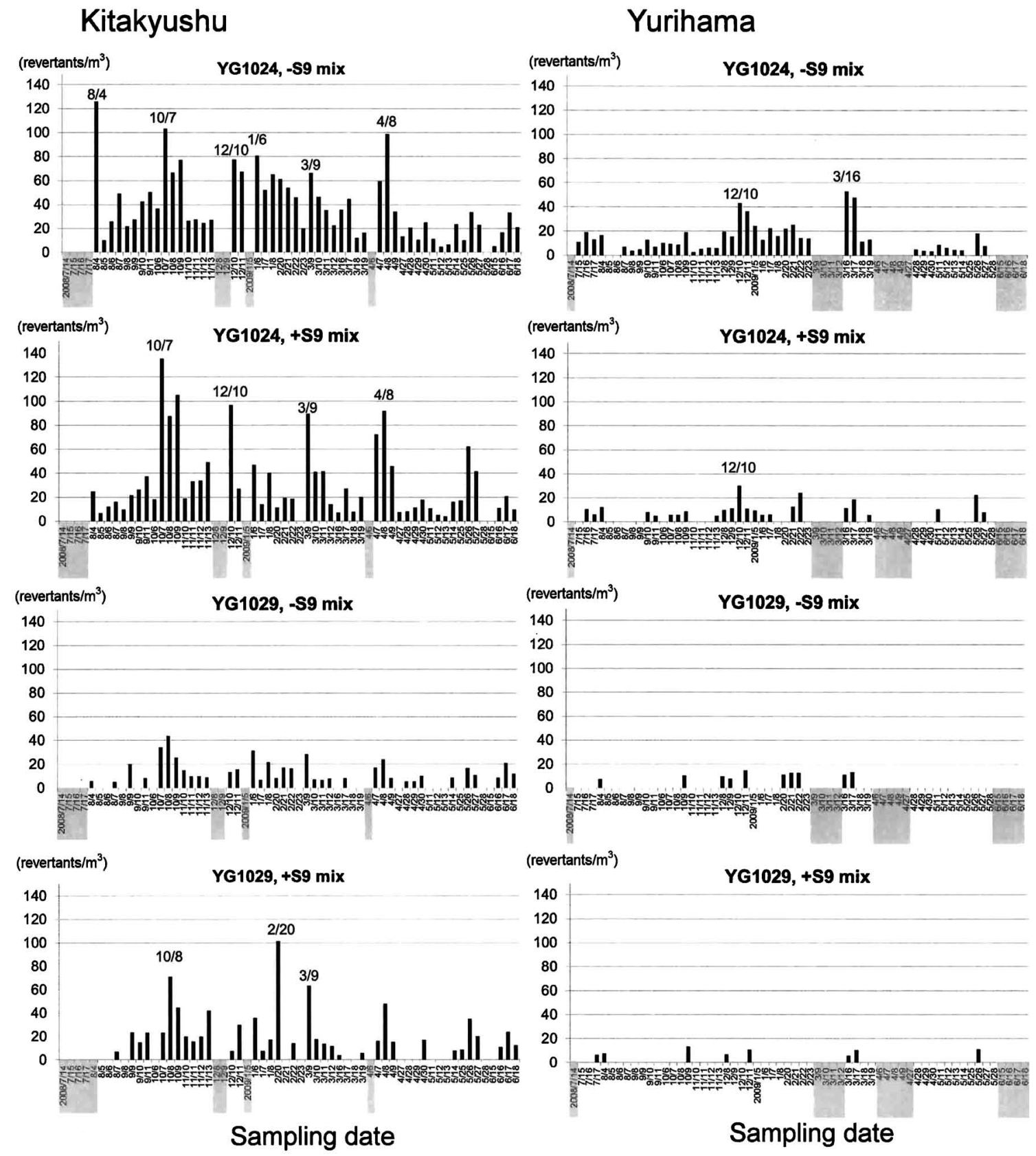

Fig. 3. Continued

Asian dust event). Extracts of airborne particles were prepared as described previously (23). The filter with particle sizes smaller than $1.1 \mu \mathrm{m}$ (corresponding to 407.5 or $509.4 \mathrm{~m}^{3}$ ) was cut into small pieces and extracted with $100 \mathrm{~mL}$ of methanol twice using an ultrasonic apparatus for 15 min each time. The filters with particle sizes larger than $1.1 \mu \mathrm{m}$ (corresponding to 815.0 or $1018.8 \mathrm{~m}^{3}$ ) were cut into small pieces and similarly extracted with $200 \mathrm{~mL}$ of methanol and $100 \mathrm{~mL}$ of it. All extracts were filtered through No. 5C filter papers and the filtrate was evaporated to dryness. Extracts were dis- solved in $10 \mathrm{~mL}$ of ethanol and $50 \mu \mathrm{L}$ of the solutions were injected into a Wakosil-PAHs column $(4.6 \mathrm{~mm} \times$ $250 \mathrm{~mm}$, Wako Pure Chemical Industries, Ltd.) for HPLC. The elution was performed with the following gradient system using solution $\mathrm{A}(80 \%$ methanol) and solution B (acetonitrile): 0-20 min, 10-75\% solution B (linear gradient with solution A); $20-30 \mathrm{~min}, \mathbf{7 5} \%$ solution $\mathrm{B}(25 \%$ solution $\mathrm{A})$, at a flow rate of $1 \mathrm{~mL} / \mathrm{min}$. The eluate was monitored using a fluorescence detector (RF-20AXS, Shimadzu, Kyoto, Japan) with the following excitation (Ex) and emission (Em) wavelengths: 
Kobe
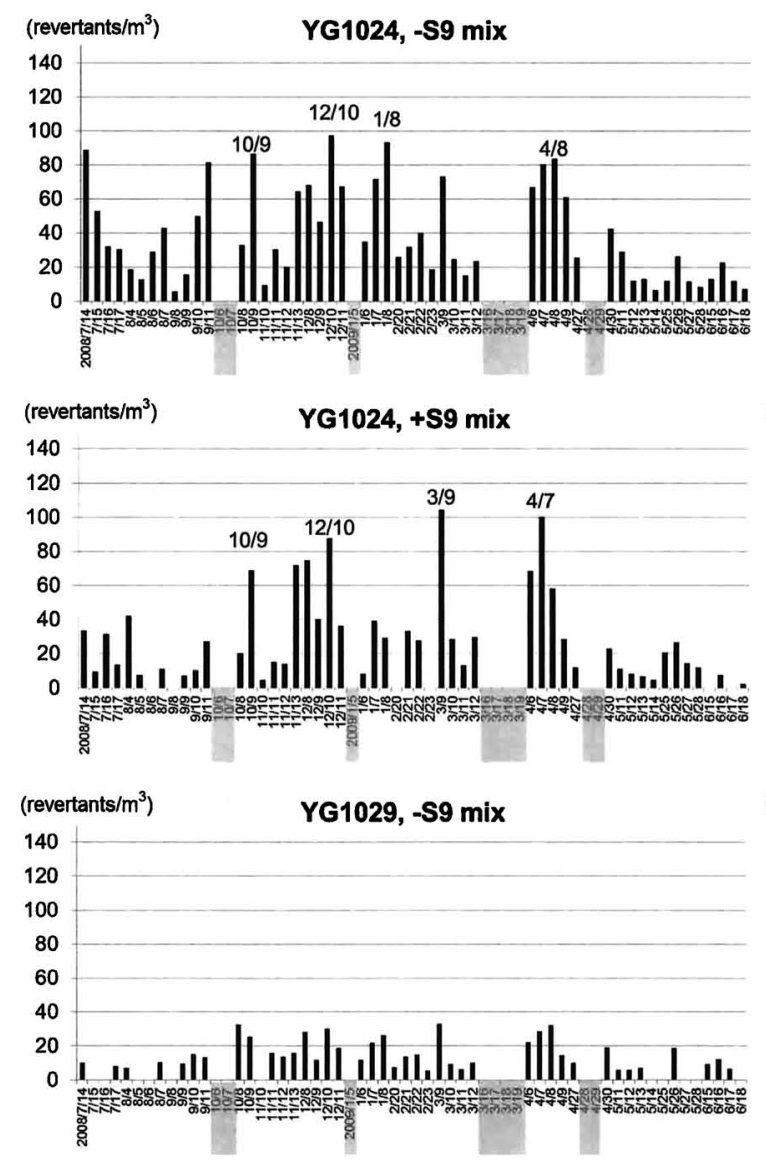

(revertants $/ \mathrm{m}^{3}$ )

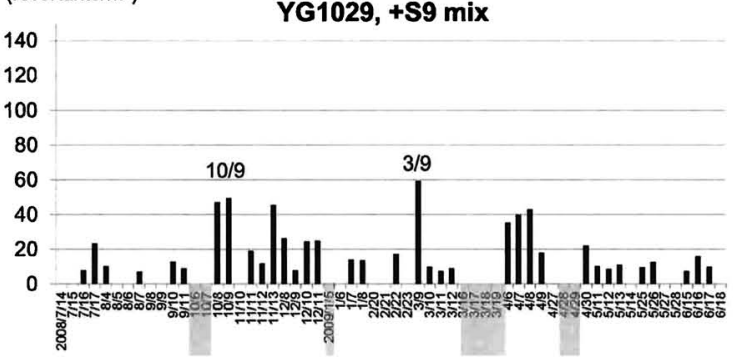

Sampling date
Osaka
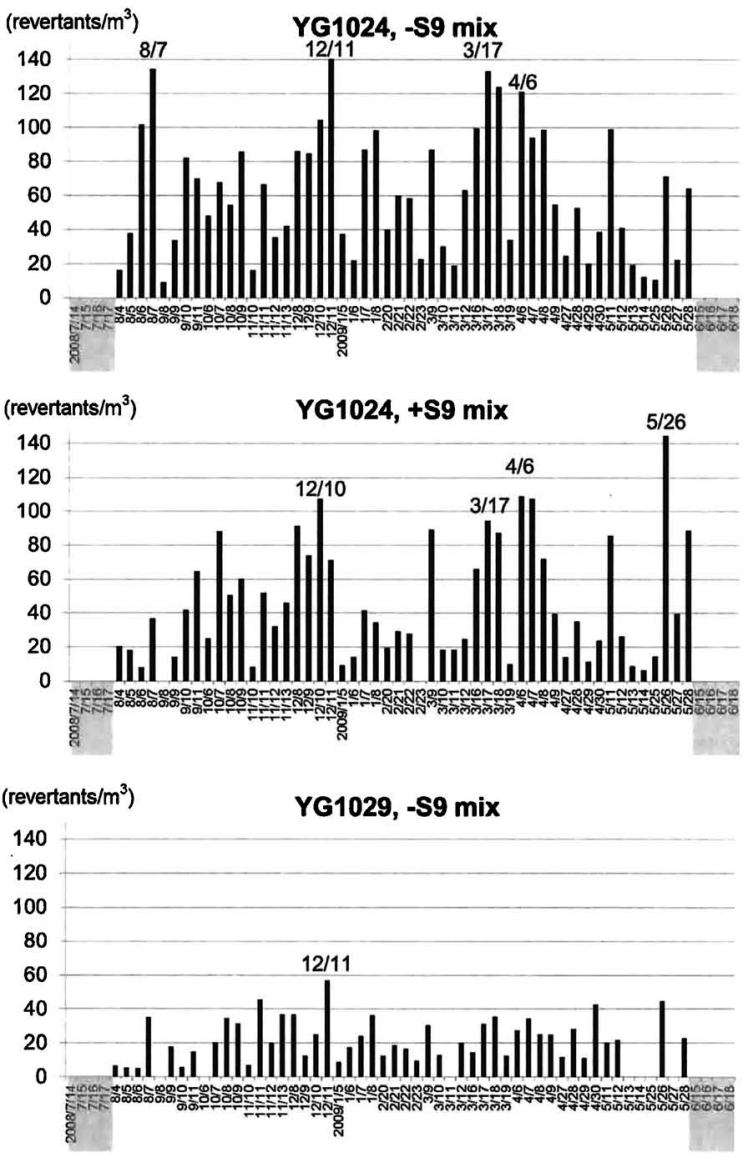

(revertants $/ \mathrm{m}^{3}$ )

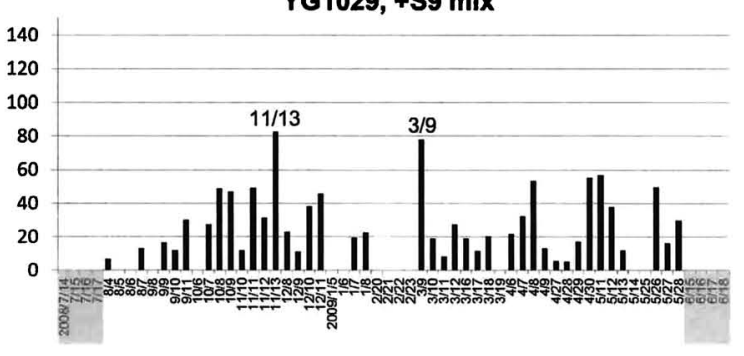

Sampling date

Fig. 3. Continued

0-11.5 min, Ex $250 \mathrm{~nm}$, Em $420 \mathrm{~nm} ; 11.5-18.75 \mathrm{~min}$, Ex $270 \mathrm{~nm}$, Em $400 \mathrm{~nm}$; 18.75-23.3 min, Ex $296 \mathrm{~nm}$, Em 410 nm; 23.3-30 min, Ex 300 nm, Em 500 nm. Contents of PAHs in samples were estimated from standard curves obtained from various doses of the authentic compounds.

Statistical analysis: Coefficients of correlation between the concentration and mutagenicity of airborne particles for each sampling site were calculated using Microsoft Office Excel 2013.

Back trajectory analysis: Back trajectory analysis was performed for each collection date and each sampling site with HYSPLIT (2010) provided by the National Oceanic and Atmospheric Administration (NOAA) of the United States of America (24). The start time of analysis was set at 10 PM (Japan Standard Time), namely, 1 PM UTC (Coordinated Universal Time), and the height was set at $1500 \mathrm{~m}$. Back trajectory analysis was calculated using model vertical velocity and the trajectory duration was $96 \mathrm{~h}$. 

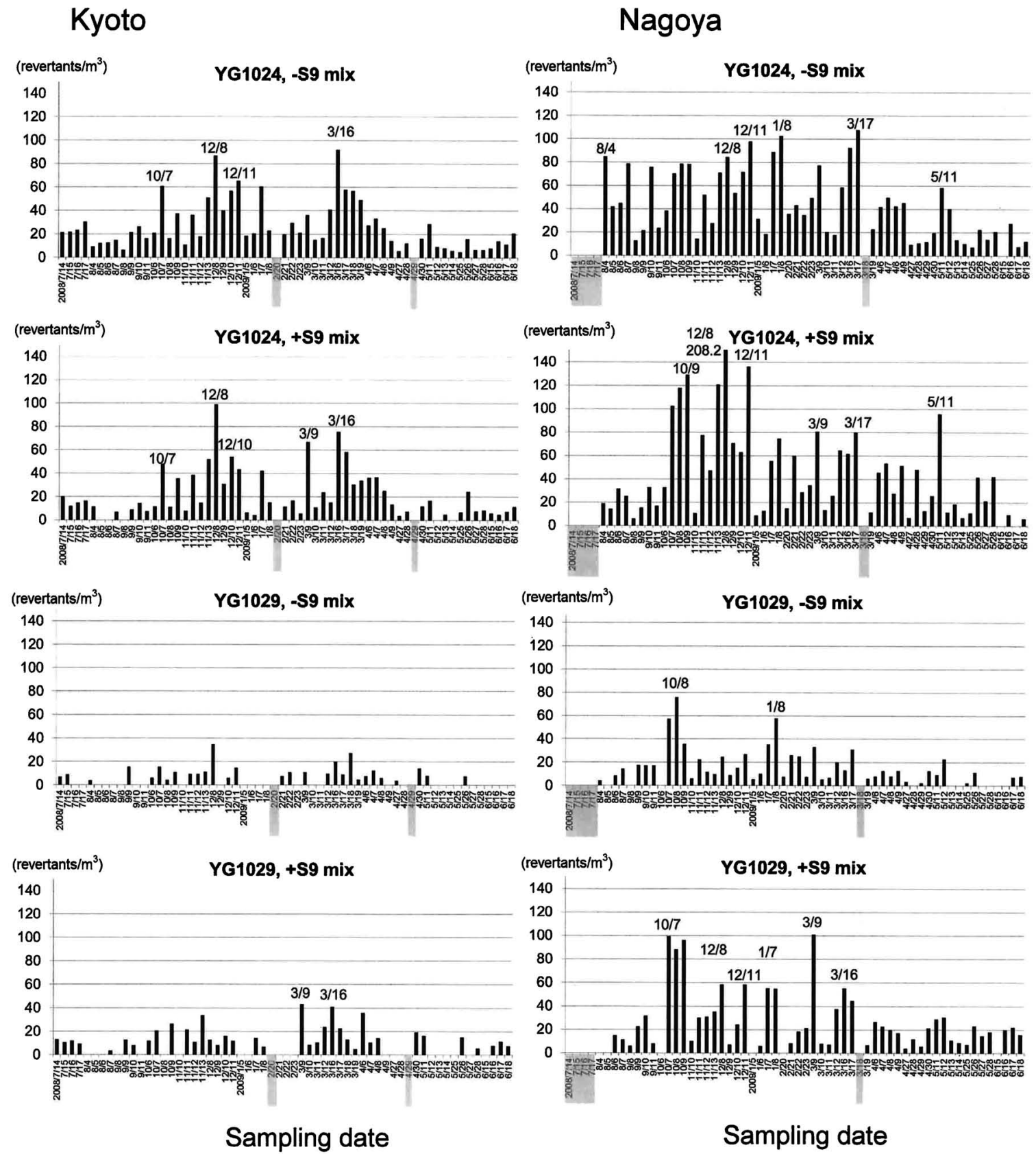

Fig. 3. Continued

\section{Results}

Daily and seasonal variation of the concentration of airborne particles: Concentrations of airborne particles collected at the 10 sites are shown in Fig. 2. Numbers of sampling days at the 10 sites ranged from 46 to 58 days. The numbers of sampling days at each site and sampling dates when the concentrations of airborne particles were higher than $100 \mu \mathrm{g} / \mathrm{m}^{3}$ are listed in Table 2 . The particle concentrations at each site were about 50 $\mu \mathrm{g} / \mathrm{m}^{3}$ or less on most sampling dates. Very high particle concentrations $\left(>150 \mu \mathrm{g} / \mathrm{m}^{3}\right)$ were found at 5 and 6 sites on March 16 and 17, respectively. At 4 sites, namely, Yurihama, Osaka, Kyoto, and Nagoya, particle concentrations were the highest, from 177 to $227 \mu \mathrm{g} / \mathrm{m}^{3}$ air, on March 16, 2009. At Kanazawa, the second highest concentration of airborne particles was seen on March 16. On December 10 and 11, 2008, and February 20 and April 7, 2009, high particle concentrations ( $>100$ $\mu \mathrm{g} / \mathrm{m}^{3}$ ) were seen at 4 sites on each day.

The mean values of airborne particle concentrations at the 10 the sites in each season and year are shown in Table 3. The highest concentrations of airborne parti- 
Kanazawa
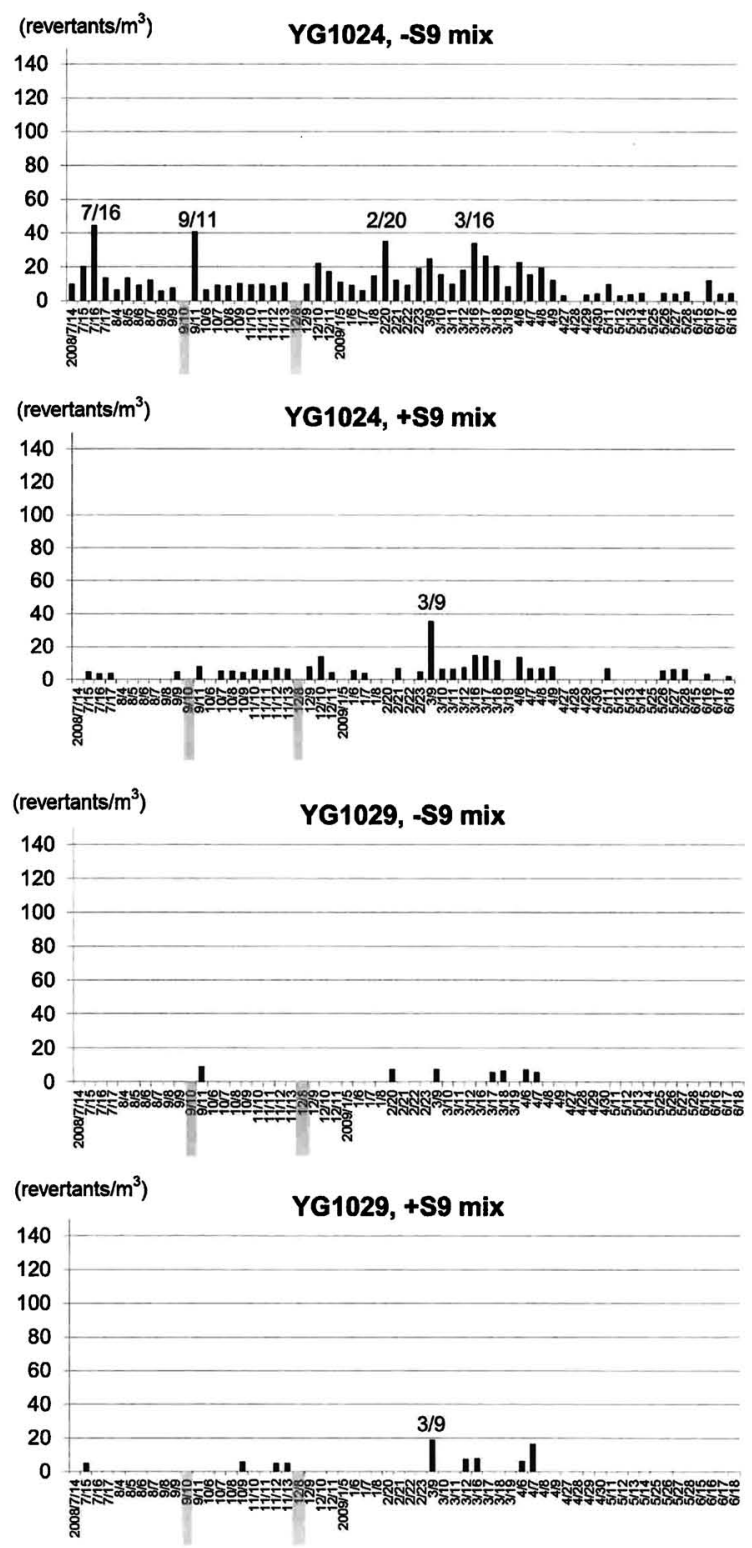

Sampling date
Wako
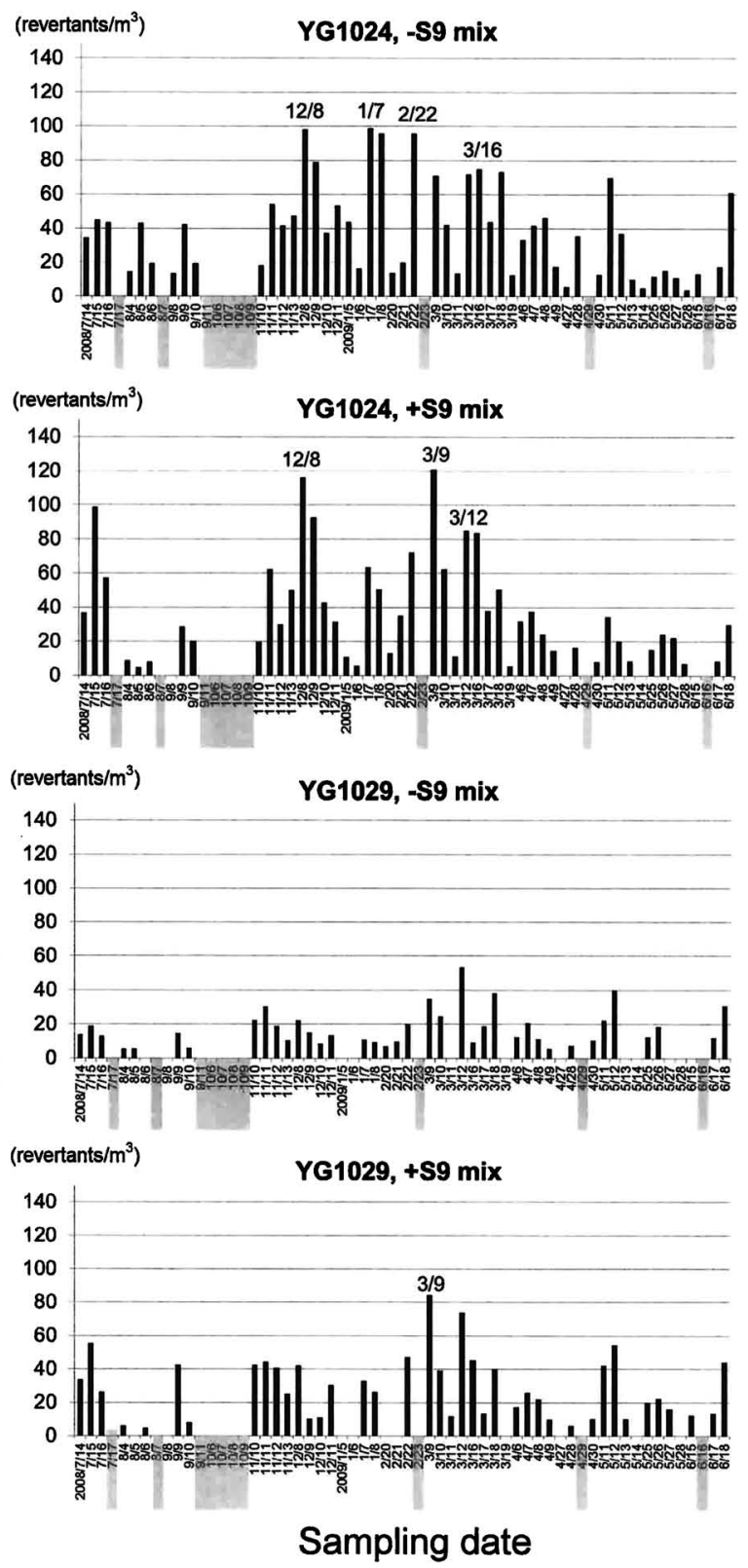

Fig. 3. Continued cles were observed in spring at 9 sites and the concentrations ranged from 63 to $75 \mu \mathrm{g} / \mathrm{m}^{3}$. The second highest mean values were found in winter at 8 sites (from 42 to $64 \mu \mathrm{g} / \mathrm{m}^{3}$ ). The lowest concentration of airborne particles was detected in summer or autumn at 5 sites each.

Daily and seasonal variation of the mutagenicity of airborne particles: Figure 3 shows the mutagenicities of organic extracts of airborne particles collected at the 10 sites in YG1024 and YG1029 with and without S9 mix. Most samples from the 10 sites were mutagenic in YG1024 with and without S9 mix, and most samples showed higher activities without S9 mix than with it. Although many samples showed mutagenicity in YG1029, the potencies were generally lower than those in YG1024. Mutagenicity levels of airborne particles (the highest mutagenicies and numbers of samples that showed potent mutagenicity) were quite different among the sampling sites. At Yurihama, the mutagenicity level of airborne particles was low, but 3 samples, collected on December 10, 2008, and March 16 and 17, 2009, showed relatively high mutagenicity, between 40 and 80 revertants $/ \mathrm{m}^{3}$, in YG1024 without S9 mix. The sam- 
Table 4. Sampling dates of airborne particles inducing more than 40 revertants $/ \mathrm{m}^{3}$ in YG1024

\begin{tabular}{|c|c|c|c|c|c|c|c|c|c|c|c|c|c|}
\hline \multirow{2}{*}{$\underset{\text { site }}{\text { Sampling }}$} & \multicolumn{6}{|c|}{2008} & \multicolumn{6}{|c|}{2009} & \multirow{2}{*}{$\begin{array}{c}\text { Number of } \\
\text { days }\end{array}$} \\
\hline & Jul. & Aug. & Sep. & Oct. & Nov. & Dec. & Jan. & Feb. & Mar. & Apr. & May & Jun. & \\
\hline \multicolumn{14}{|c|}{ without $\mathrm{S} 9 \mathrm{mix}$} \\
\hline Sasebo & - & 7 & - & 7 & - & - & $5,6,8$ & - & 10,16 & 7 & - & - & 8 \\
\hline Dazaifu & - & - & - & 7 & - & 10,11 & $5,6,7,8$ & 20,21 & 16 & $6,7,8,9$ & 14 & - & 15 \\
\hline Kitakyushu & $u-$ & 4,7 & 10,11 & $7,8,9$ & - & 10,11 & $6,7,8$ & $20,21,22$ & $9,10,17$ & 7,8 & - & - & 20 \\
\hline Yurihama & - & - & - & - & - & 10 & - & - & $16,1 \overline{7}$ & - & - & - & 3 \\
\hline Kobe & 14,15 & 7 & 10,11 & 9 & 13 & $8,9,10,11$ & 7,8 & - & 9 & $6,7,8,9,30$ & - & - & 19 \\
\hline Osaka & - & 6,7 & 10,11 & $6,7,8,9$ & 11,13 & $8,9,10,11$ & 7,8 & 20,21 & $9,12,16,17,18$ & $6,7,8,9,28$ & $11,12,26,28$ & - & 32 \\
\hline Kyoto & - & - & - & 7 & 13 & $8,10,11$ & 7 & - & $12,16, \overline{17}, \overline{18}, \overline{19}$ & - & - & - & 11 \\
\hline Nagoya & - & $4,5,6,7$ & 10 & $7,8,9$ & 11,13 & $8,9,10,11$ & 7,8 & 21,23 & $9,12,16,17$ & $6,7,8,9$ & 11 & - & 27 \\
\hline Kanazawa & 16 & - & 11 & - & - & - & - & - & -- & - & - & - & 2 \\
\hline $\begin{array}{l}\text { Wako } \\
\text { with S9 mix }\end{array}$ & 15,16 & 5 & 9 & - & $11,12,13$ & $8,9,11$ & $5,7,8$ & 22 & $9,10,12,16, \underline{17}, \underline{18}$ & 7,8 & 11 & 18 & 24 \\
\hline Sasebo & - & - & - & 7 & - & - & 6 & - & 10,19 & 7 & - & - & 5 \\
\hline Dazaifu & - & - & - & 7,9 & - & 8,10 & $5,6,7,8$ & - & - & $7,8,9$ & - & - & 11 \\
\hline Kitakyushu & $\mathrm{u}-$ & - & - & $7,8,9$ & 13 & 10 & 6,8 & - & $9,10,11$ & $7,8,9$ & 26,27 & - & 15 \\
\hline Yurihama & - & - & - & - & - & - & - & - & - & - & - & - & 0 \\
\hline Kobe & - & 4 & - & 9 & 13 & $8,9,10$ & - & - & 9 & $6,7,8$ & - & - & 10 \\
\hline Osaka & - & - & 10,11 & $7,8,9$ & 11,13 & $8,9,10,11$ & 7 & - & $9,16,17,18$ & $6,7,8$ & $11,26,28$ & - & 22 \\
\hline Kyoto & - & - & - & 7 & 13 & $8,10,11$ & 7 & - & $9,16,17$ & - & - & - & 9 \\
\hline Nagoya & - & - & - & $7,8,9$ & $11,12,13$ & $8,9,10,11$ & 7,8 & 21 & $9,12,16,17$ & $6,7,9,28$ & $11,26,28$ & - & 24 \\
\hline Kanazawa & - & - & - & - & - & - & - & - & -- & - & - & - & 0 \\
\hline Wako & 15,16 & - & - & - & 11,13 & $8,9,10$ & 7,8 & 22 & $9,10,12,16, \underline{18}$ & - & - & - & 15 \\
\hline
\end{tabular}

The dates when Asian dust arrived as reported by the Japan Meteorological Agency (25) are underlined.

pling dates of airborne particles that induced more than 40 revertants $/ \mathrm{m}^{3}$ in YG1024 without S9 mix are shown in Table 4. At Kitakyushu, Kobe, Osaka, Nagoya, and Wako, about 20 samples or more induced $>40$ revertants $/ \mathrm{m}^{3}$ in YG1024 without S9 mix. At Sasebo, Dazaifu, and Kyoto, the numbers of sampling dates of particles inducing $>40$ revertants $/ \mathrm{m}^{3}$ were moderate, from 8 to 15 days. Only 2 samples from Kanazawa induced $>40$ revertants $/ \mathrm{m}^{3}$. As shown in Fig. 3, many samples collected at Osaka and Nagoya showed high mutagenicity, inducing more than 80 revertants $/ \mathrm{m}^{3}$, in YG1024 without S9 mix. Airborne particles collected at 7 sites on March 16, 2009, induced $>40$ revertants $/ \mathrm{m}^{3}$, and those from Sasebo, Osaka, Kyoto, and Nagoya showed high mutagenicity, $>80$ revertants $/ \mathrm{m}^{3}$. Similarly, airborne particles collected at 6 sites on March 17, 2009 , induced $>40$ revertants $/ \mathrm{m}^{3}$, and those from Osaka and Nagoya showed high mutagenicity. Relatively high or high mutagenicities were detected for 7 samples collected on December 10 and 11, 2008.

Table 5 shows seasonal and annual mean values of the mutagenicities of airborne particles from the 10 sites in YG1024 and YG1029 with and without S9 mix. The highest annual means were observed in YG1024 without $\mathrm{S} 9 \mathrm{mix}$ at 9 sites. The annual means of the 10 sites in YG1024 without S9 mix were quite different among the sampling sites. Low annual means were seen at Kanazawa and Yurihama, 12.2 and 13.1 revertants $/ \mathrm{m}^{3}$, respectively, and high means were observed at Kitakyushu,
Kobe, Osaka, Nagoya, and Wako, from 38.1 to 60.9 revertants $/ \mathrm{m}^{3}$. For the seasonal means in YG1024 without $\mathrm{S} 9 \mathrm{mix}$, the highest values were observed in winter at 9 sites, and the second highest values were found in autumn and spring at 5 and 3 sites, respectively.

Correlation between the concentration and mutagenicity of airborne particles: Coefficients of correlation between the concentration and mutagenicity of airborne particles at each sampling site in each season and year are shown in Table 6. In YG1024 without S9 mix, a positive correlation (correlation coefficients were larger than 0.4 ) were observed at 8 sites in spring, and correlation coefficients were larger than 0.6 at 6 sites, namely, Dazaifu, Yurihama, Osaka, Kyoto, Nagoya, and Kanazawa. Figure 4 shows the correlation between the concentration and mutagenicity of airborne particles collected at these 6 sites in spring. The correlation coefficient for Yurihama was especially large, 0.909. In autumn and winter, large correlation coefficients $(>0.6)$ were found at 4 sites, namely, Dazaifu, Kitakyushu, Kobe, and Osaka, and 2 sites, namely, Osaka and Nagoya, respectively. The correlation coefficient for Yurihama in year was 0.668 . In YG1024 with S9 mix, high correlation coefficients were observed at 4 sites in autumn.

Back trajectory analysis: Figure 5 shows the results of back trajectory analysis of the air masses of 8 sites for March 16, 2009. Dazaifu and Kitakyushu are located in Fukuoka prefecture. The distance between 
Table 5. Mutagenicity of airborne particles at the 10 sites in the four seasons and annually

\begin{tabular}{|c|c|c|c|c|c|c|c|c|}
\hline \multirow{3}{*}{ Period } & \multicolumn{4}{|c|}{ Sasebo } & \multicolumn{4}{|c|}{ Dazaifu } \\
\hline & \multicolumn{2}{|c|}{ YG1024 } & \multicolumn{2}{|c|}{ YG1029 } & \multicolumn{2}{|c|}{ YG1024 } & \multicolumn{2}{|c|}{ YG1029 } \\
\hline & -S9 mix & +S9 mix & -S9 mix & +S9 mix & -S9 mix & + S9 mix & -S9 mix & + S9 mix \\
\hline Summer & $16.1 \pm 19.5$ & $6.4 \pm 5.9$ & $0.0 \pm 0.0$ & $0.4 \pm 1.3$ & $15.1 \pm 9.2$ & $9.3 \pm 8.8$ & $4.0 \pm 4.6$ & $4.3 \pm 8.2$ \\
\hline Autumn & $14.8 \pm 10.7$ & $14.8 \pm 18.3$ & $4.0 \pm 7.2$ & $6.1 \pm 8.5$ & $24.7 \pm 16.1$ & $20.3 \pm 18.8$ & $4.1 \pm 5.6$ & $5.4 \pm 5.3$ \\
\hline Winter & $48.6 \pm 39.4$ & $21.4 \pm 16.6$ & $13.9 \pm 8.4$ & $5.8 \pm 7.4$ & $60.5 \pm 31.4$ & $39.4 \pm 23.8$ & $8.6 \pm 3.5$ & $1.0 \pm 3.2$ \\
\hline Spring & $23.5 \pm 23.1$ & $14.9 \pm 15.9$ & $3.9 \pm 5.3$ & $4.9 \pm 7.5$ & $28.9 \pm 23.3$ & $20.1 \pm 21.4$ & $6.0 \pm 6.2$ & $6.9 \pm 7.9$ \\
\hline Year & $23.6 \pm 25.4$ & $13.9 \pm 15.3$ & $4.6 \pm 7.1$ & $4.2 \pm 7.0$ & $31.3 \pm 26.3$ & $21.7 \pm 21.3$ & $5.7 \pm 5.4$ & $4.8 \pm 6.9$ \\
\hline \multirow{3}{*}{ Period } & \multicolumn{4}{|c|}{ Yurihama } & \multicolumn{4}{|c|}{ Kobe } \\
\hline & \multicolumn{2}{|c|}{ YG1024 } & \multicolumn{2}{|c|}{ YG1029 } & \multicolumn{2}{|c|}{ YG1024 } & \multicolumn{2}{|c|}{ YG1029 } \\
\hline & $-\mathrm{S} 9$ mix & + S9 mix & -S9 mix & $+\mathrm{S} 9$ mix & $-\mathrm{S} 9$ mix & + S9 mix & $-\mathrm{S} 9$ mix & $+\mathrm{S} 9$ mix \\
\hline Summer & $9.3 \pm 7.4$ & $4.0 \pm 5.4$ & $1.1 \pm 2.8$ & $2.0 \pm 3.4$ & $29.9 \pm 22.8$ & $13.0 \pm 14.4$ & $5.3 \pm 4.9$ & $6.7 \pm 7.4$ \\
\hline Autumn & $7.7 \pm 4.5$ & $3.1 \pm 3.4$ & $0.9 \pm 3.0$ & $1.1 \pm 3.8$ & $39.4 \pm 29.4$ & $23.7 \pm 25.6$ & $14.1 \pm 10.0$ & $19.4 \pm 20.2$ \\
\hline Winter & $21.8 \pm 9.4$ & $9.8 \pm 9.2$ & $5.7 \pm 6.1$ & $1.4 \pm 3.5$ & $53.9 \pm 26.9$ & $34.0 \pm 27.5$ & $17.3 \pm 8.4$ & $11.6 \pm 10.7$ \\
\hline Spring & $12.2 \pm 16.1$ & $5.1 \pm 7.5$ & $1.6 \pm 4.2$ & $1.8 \pm 3.9$ & $34.0 \pm 26.6$ & $31.4 \pm 30.7$ & $12.3 \pm 11.0$ & $16.4 \pm 17.0$ \\
\hline Year & $13.1 \pm 12.0$ & $5.6 \pm 7.2$ & $2.4 \pm 4.7$ & $1.5 \pm 3.6$ & $38.4 \pm 27.1$ & $26.1 \pm 26.5$ & $12.1 \pm 9.8$ & $13.7 \pm 15.1$ \\
\hline \multirow{3}{*}{ Period } & \multicolumn{4}{|c|}{ Kyoto } & \multicolumn{4}{|c|}{ Nagoya } \\
\hline & \multicolumn{2}{|c|}{ YG1024 } & \multicolumn{2}{|c|}{ YG1029 } & \multicolumn{2}{|c|}{ YG1024 } & \multicolumn{2}{|c|}{ YG1029 } \\
\hline & $-\mathrm{S} 9 \operatorname{mix}$ & $+\mathrm{S} 9 \operatorname{mix}$ & $-\mathrm{S} 9 \operatorname{mix}$ & +S9 mix & $-\mathrm{S} 9 \operatorname{mix}$ & $+\mathrm{S} 9$ mix & -S9 mix & $+\mathrm{S} 9$ mix \\
\hline Summer & $16.5 \pm 6.7$ & $9.1 \pm 6.2$ & $1.7 \pm 3.2$ & $6.2 \pm 5.2$ & $36.9 \pm 31.6$ & $13.0 \pm 11.4$ & $5.3 \pm 5.2$ & $10.3 \pm 9.1$ \\
\hline Autumn & $26.7 \pm 16.5$ & $20.7 \pm 17.6$ & $6.9 \pm 6.0$ & $12.0 \pm 11.3$ & $46.8 \pm 26.7$ & $58.8 \pm 47.5$ & $22.7 \pm 23.1$ & $38.1 \pm 35.9$ \\
\hline Winter & $40.0 \pm 23.7$ & $29.8 \pm 28.7$ & $6.7 \pm 10.6$ & $6.3 \pm 6.5$ & $59.1 \pm 28.6$ & $63.7 \pm 57.6$ & $21.0 \pm 15.2$ & $25.9 \pm 23.9$ \\
\hline Spring & $25.3 \pm 22.0$ & $22.4 \pm 21.0$ & $6.2 \pm 7.3$ & $12.4 \pm 13.5$ & $35.1 \pm 28.0$ & $37.0 \pm 26.3$ & $9.7 \pm 9.5$ & $23.0 \pm 21.5$ \\
\hline Year & $26.6 \pm 20.0$ & $20.7 \pm 20.7$ & $5.5 \pm 7.3$ & $9.9 \pm 10.8$ & $43.2 \pm 29.2$ & $44.1 \pm 41.6$ & $14.4 \pm 15.6$ & $25.1 \pm 25.5$ \\
\hline \multirow{3}{*}{ Period } & \multicolumn{4}{|c|}{ Wako } & \multicolumn{4}{|c|}{10 sites } \\
\hline & \multicolumn{2}{|c|}{ YG1024 } & \multicolumn{2}{|c|}{ YG1029 } & \multicolumn{2}{|c|}{ YG1024 } & \multicolumn{2}{|c|}{ YG1029 } \\
\hline & $-\mathrm{S} 9$ mix & $+\mathrm{S} 9 \mathrm{mix}$ & $-\mathrm{S} 9 \operatorname{mix}$ & $+\mathrm{S} 9 \operatorname{mix}$ & $-\mathrm{S} 9 \operatorname{mix}$ & $+\mathrm{S} 9$ mix & -S9 mix & $+\mathrm{S} 9$ mix \\
\hline Summer & $32.1 \pm 17.0$ & $27.8 \pm 32.5$ & $10.9 \pm 9.7$ & $21.6 \pm 19.2$ & $24.0 \pm 25.2$ & $10.8 \pm 14.2$ & $4.0 \pm 6.5$ & $6.0 \pm 9.8$ \\
\hline Autumn & $33.4 \pm 16.3$ & $29.8 \pm 20.6$ & $14.6 \pm 10.3$ & $28.8 \pm 18.3$ & $29.8 \pm 24.1$ & $26.4 \pm 30.6$ & $10.0 \pm 13.4$ & $16.2 \pm 21.5$ \\
\hline Winter & $58.9 \pm 35.1$ & $48.3 \pm 35.1$ & $10.5 \pm 7.0$ & $18.1 \pm 18.1$ & $48.4 \pm 31.5$ & $32.9 \pm 34.3$ & $12.2 \pm 11.4$ & $10.7 \pm 17.2$ \\
\hline Spring & $32.7 \pm 25.0$ & $31.1 \pm 30.8$ & $14.7 \pm 15.1$ & $24.4 \pm 23.2$ & $29.7 \pm 27.7$ & $25.6 \pm 28.4$ & $8.5 \pm 10.8$ & $13.4 \pm 17.6$ \\
\hline Year & $38.4 \pm 27.1$ & $34.1 \pm 31.0$ & $13.1 \pm 12.0$ & $23.1 \pm 20.5$ & $32.5 \pm 28.6$ & $24.6 \pm 29.0$ & $8.8 \pm 11.2$ & $12.1 \pm 17.6$ \\
\hline
\end{tabular}

Numbers express mean values $\left(\mathrm{rev} . / \mathrm{m}^{3}\right) \pm$ standard deviation.

the sampling sites in these cities was $43 \mathrm{~km}$, so that trajectories from these sites were quite similar. Trajectories from 7 sites, namely, Sasebo, Dazaifu, Kitakyushu, Yurihama, Osaka, Kanazawa, and Wako, indicate that air masses at these sites had transferred from the northwest of China or southern Mongolia, namely, the Gobi desert, without a large detour. For Kyoto and Nagoya, the trajectories suggest that air masses had transferred from the central or eastern areas of Mongolia to Zhejiang province and it environs in China, and then been carried to each site in Japan. For March 17, 2009, the trajectories of air masses for each site indicate that air masses of all sites were transferred through the Gobi desert and reached each site without an obvious detour (data not shown). Airborne particles were not collected in Kobe on those days.

Size distributions of airborne particles and PAHs: Figure 6(A) shows the size distributions of airborne particles collected in Kyoto from January 17 to 21, 2011 (without an Asian dust event) and from May 1 to 6, 2011 (with an Asian dust event). The size distributions are shown as the ratios of weights of particles classified into 5 types, namely, <1.1, 1.1-2.0, 2.0-3.3, 3.3-7.0, and $>7.0 \mu \mathrm{m}$. For the period without an Asian dust event (January 17-21, 2011), the smallest particles $(<1.1 \mu \mathrm{m})$ were the most abundant and accounted for $70 \%$ of the total. Large size fractions of $>7.0$ and $3.3-7.0 \mu \mathrm{m}$ accounted for only $8 \%$ and $14 \%$, respec- 
Table 6. Coefficients of correlation between the concentration and mutagenicity of airborne particles

\begin{tabular}{|c|c|c|c|c|c|c|c|c|c|c|}
\hline \multirow{2}{*}{ Sampling site } & \multicolumn{5}{|c|}{ YG1024, - S9 mix } & \multicolumn{5}{|c|}{ YG1024, + S9 mix } \\
\hline & Summer & Autumn & Winter & Spring & Year & Summer & Autumn & Winter & Spring & Year \\
\hline Sasebo & -0.098 & 0.408 & -0.124 & 0.285 & 0.153 & -0.434 & 0.372 & -0.373 & 0.239 & 0.083 \\
\hline Dazaifu & 0.229 & 0.730 & -0.209 & 0.644 & 0.292 & 0.108 & 0.792 & -0.257 & 0.602 & 0.272 \\
\hline Kitakyushu & 0.351 & 0.774 & 0.390 & 0.485 & 0.287 & 0.549 & 0.627 & 0.320 & 0.320 & 0.263 \\
\hline Yurihama & 0.346 & 0.455 & 0.496 & 0.909 & 0.668 & 0.297 & 0.704 & 0.048 & 0.416 & 0.249 \\
\hline Kobe & -0.293 & 0.786 & 0.294 & 0.530 & 0.374 & -0.373 & 0.407 & 0.413 & 0.373 & 0.410 \\
\hline Osaka & -0.618 & 0.718 & 0.649 & 0.709 & 0.553 & 0.492 & 0.649 & 0.558 & 0.408 & 0.473 \\
\hline Kyoto & -0.180 & -0.158 & 0.053 & 0.749 & 0.353 & -0.471 & -0.349 & -0.015 & 0.589 & 0.226 \\
\hline Nagoya & -0.495 & 0.329 & 0.600 & 0.828 & 0.481 & -0.249 & 0.108 & 0.527 & 0.501 & 0.316 \\
\hline Kanazawa & 0.285 & -0.004 & 0.394 & 0.669 & 0.378 & 0.431 & 0.296 & 0.665 & 0.330 & 0.415 \\
\hline Wako & 0.553 & 0.171 & 0.241 & 0.302 & 0.165 & 0.644 & 0.166 & 0.357 & -0.045 & 0.084 \\
\hline \multirow{2}{*}{ Sampling site } & \multicolumn{5}{|c|}{ YG1029, -S9 mix } & \multicolumn{5}{|c|}{ YG1029, + S9 mix } \\
\hline & Summer & Autumn & Winter & Spring & Year & Summer & Autumn & Winter & Spring & Year \\
\hline Sasebo & NA & 0.190 & -0.293 & 0.379 & 0.121 & -0.064 & 0.102 & -0.341 & 0.329 & 0.082 \\
\hline Dazaifu & 0.503 & 0.802 & 0.048 & 0.488 & 0.396 & 0.306 & 0.497 & 0.274 & 0.588 & 0.344 \\
\hline Kitakyushu & 0.775 & 0.279 & -0.175 & 0.274 & 0.081 & 0.623 & -0.045 & 0.706 & 0.068 & 0.286 \\
\hline Yurihama & -0.170 & 0.188 & 0.314 & 0.931 & 0.464 & 0.049 & 0.188 & -0.044 & 0.534 & 0.287 \\
\hline Kobe & 0.334 & 0.363 & 0.244 & 0.394 & 0.369 & 0.261 & 0.257 & 0.378 & 0.450 & 0.368 \\
\hline Osaka & 0.086 & 0.179 & 0.578 & 0.263 & 0.270 & 0.420 & 0.342 & 0.701 & 0.022 & 0.165 \\
\hline Kyoto & 0.058 & -0.132 & -0.047 & 0.602 & 0.274 & -0.272 & -0.173 & 0.080 & 0.363 & 0.211 \\
\hline Nagoya & -0.332 & 0.227 & 0.270 & 0.510 & 0.190 & -0.218 & 0.174 & 0.507 & 0.555 & 0.338 \\
\hline Kanazawa & NA & -0.037 & 0.057 & 0.271 & 0.198 & -0.064 & 0.861 & NA & 0.181 & 0.182 \\
\hline Wako & 0.541 & -0.145 & 0.579 & 0.308 & 0.339 & 0.537 & -0.082 & 0.521 & 0.182 & 0.233 \\
\hline
\end{tabular}

NA: Not Available.

tively. In contrast, large size fractions were the major fractions for the period including an Asian dust event, and $>7.0$ and $3.3-7.0 \mu \mathrm{m}$ size fractions accounted for 25 and $29 \%$, respectively. The smallest size fraction was $18 \%$. Figure 6(B) shows the size distributions of PAHs in the airborne particles collected in two periods described above. Ten PAHs, namely, BaP, BbF, BkF, IcdP, BaA, DahA, FR, PY, CHR, and BghiP, were analyzed by HPLC using a fluorescence detector. PAHs were detected at retention times as follows: FR, 9.3 min; PY, 10.2 min; $\mathrm{BaA}, 13.2 \mathrm{~min}$; $\mathrm{CHR}, 14.3 \mathrm{~min}$; $\mathrm{BbF}$, 16.6 min; BkF, 18.2 min; BaP 19.6 min; DahA, 21.7 min; BghiP, $22.7 \mathrm{~min}$; and IcdP, $23.8 \mathrm{~min}$. The size distributions of PAHs are shown as ratios of the total weights of 10 PAHs detected in each size fraction. As shown in Fig. 6(B), $78 \%$ and $10 \%$ of total PAHs were detected in small size fractions of $<1.1$ and $1.1-2.0 \mu \mathrm{m}$, respectively, for the period without an Asian dust event. Similarly, 61 and $18 \%$ of PAHs were found in small size fractions of $<1.1$ and $1.1-2.0 \mu \mathrm{m}$, respectively, for the period including an Asian dust event.

\section{Discussion}

In the present study, we collected airborne particles at 10 sites in central and western areas of Japan. These 10 sites can be classified into 3 groups: metropolitan areas, moderately urbanized sites, and rural sites. Kitakyushu,
Kobe, Osaka, Kyoto, Nagoya, and Wako are in metropolitan areas, and Sasebo and Dazaifu are moderately urbanized sites. Yurihama is a rural site. Although Kanazawa is a medium-sized city, the sampling site is far from the commercial area and has few large emission sources of air pollution. Therefore the sampling site in Kanazawa is thought to be a rural site. The concentrations of airborne particles at the 10 sites were generally about $50 \mu \mathrm{g} / \mathrm{m}^{3}$ or less, and simultaneous increases of the particle concentration were found at several sites in winter and spring (Fig. 2 and Table 2). These results suggest that the fluctuations of airborne particle concentrations among the 10 sites throughout the period in this study were similar. At many sampling sites, the particle concentrations were especially high on March 16 and/or 17, 2009. On those days, Asian dust was found at many sampling sites by monitoring conducted by the Japan Meteorological Agency (25). The increased particle concentrations found in March are thought to have been caused by Asian dust. Relatively high concentration of airborne particles and mutagenicity were found at many sites on December 10 and 11, 2008, as shown in Fig. 2 and Fig. 3. Relatively high concentration of a sulfate ion were found in ambient air at those sites on those days (data not shown). A sulfate ion is a major component of fine particles, such as $\mathrm{PM}_{2.5}$, and it was reported that the concentration of a sulfate 

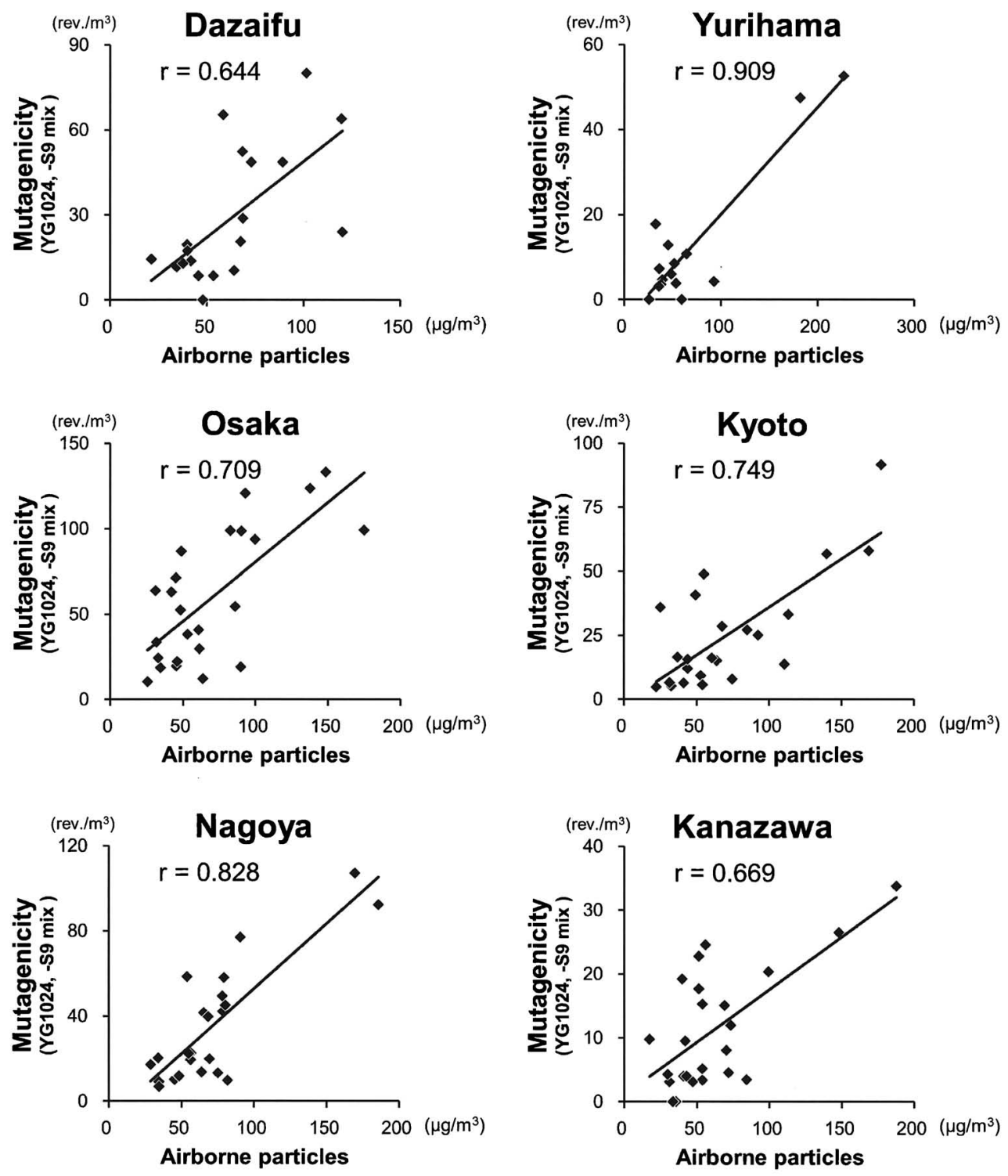

Fig. 4. Correlation between the concentration and mutagenicity of airborne particles collected at Dazaifu, Yurihama, Osaka, Kyoto, Nagoya and Kanazawa in spring 2009.

ion in ambient air was mainly effected by long-range transport of air pollution from the Asian continent $(19,26-28)$. The relatively high concentration of airborne particles and mutagenicity on December 10 and 11, 2008, may be caused by long-range transport of air pollutant. Most samples collected at the 10 sites showed the highest mutagenicity in YG1024 without S9 mix, and the potencies differed among the sampling sites (Fig. 5). The numbers of sampling dates of particles that showed relatively high or high mutagenicity were large for Kitakyushu, Kobe, Osaka, Nagoya, and Wako, moderate for Kyoto, Sasebo, and Dazaifu, and small for Yurihama and Kanazawa (Table 4). The annual means of mutagenic potencies in YG1024 without S9 mix were high for Kitakyushu, Kobe, Osaka, Nagoya, and Wako, moderate for Sasebo, Dazaifu, and Kyoto, and low for Yurihama and Kanazawa (Table 5). These results suggested that contamination levels of ambient air with mutagens were as follows: metropolitan areas $>$ moderately urbanized sites $>$ rural sites. The correlation coefficients between the concentration and mutagenicity of airborne particles collected at the 10 sites are shown in Table 6. In YG1024 without S9 mix, a positive correlation was observed in spring at most sites, and correlation coefficients were larger than 0.6 at 6 sites, namely, Dazaifu, Yurihama, Kobe, Osaka, Kyoto, Nagoya, and Kanazawa. The correlation coefficient for Yurihama was especially large, 0.909 . On the other hand, high correlation coefficients, namely, $>0.6$, were observed at only 2 sites in winter. These results suggest that the 

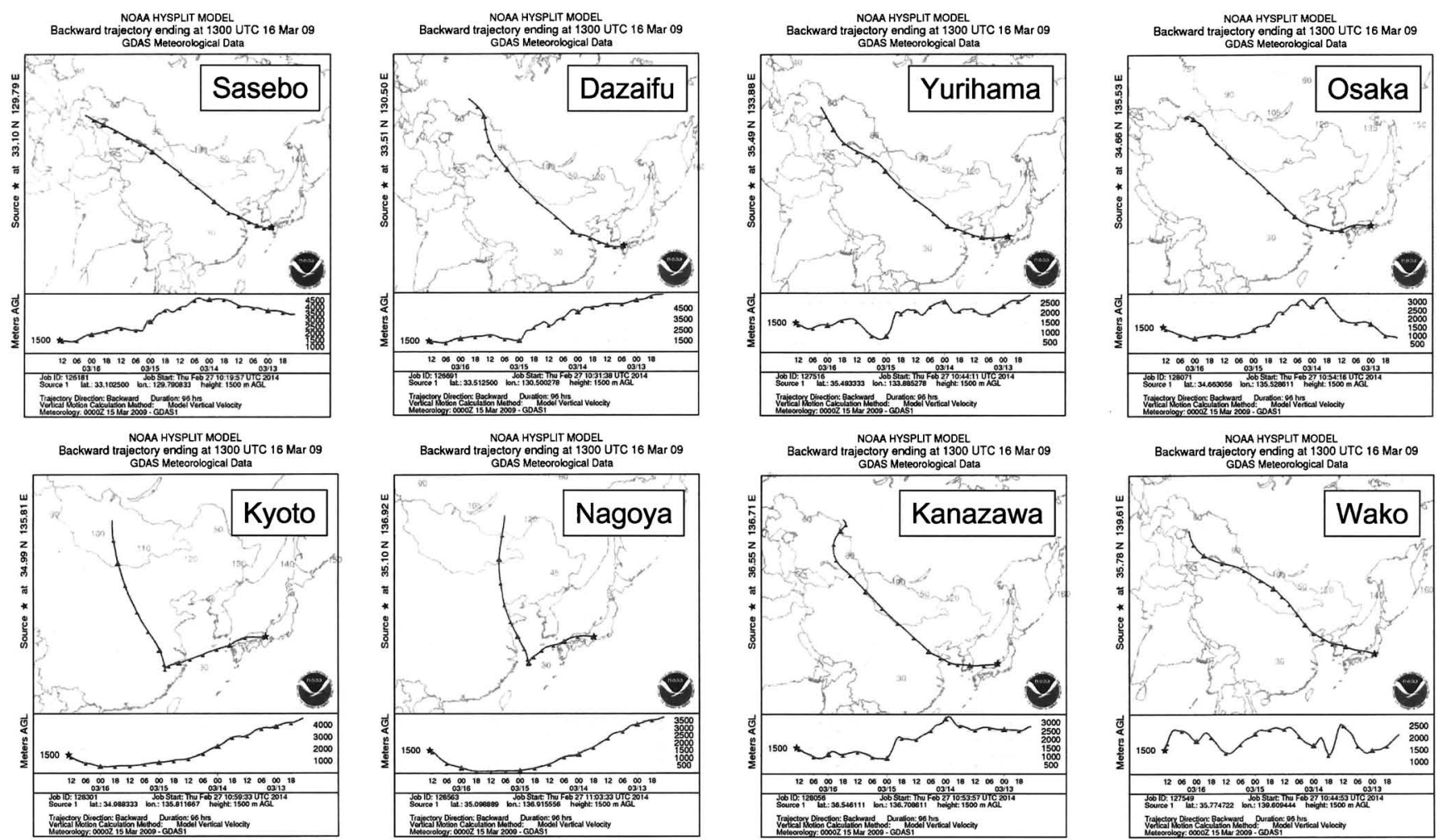

Fig. 5. Back trajectories of air masses of 8 sites from March 16, 2009, for 96 h. Back trajectory analysis was performed with HYSPLIT (2010) provided the NOAA of the USA (24).

A

Jan. 17-21, 2011

May 1-6, 2011

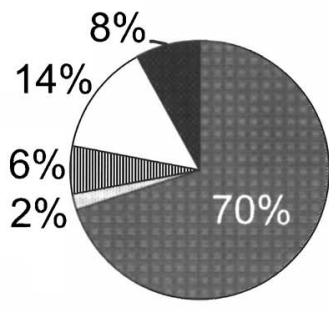

B

Jan. 17-21, 2011
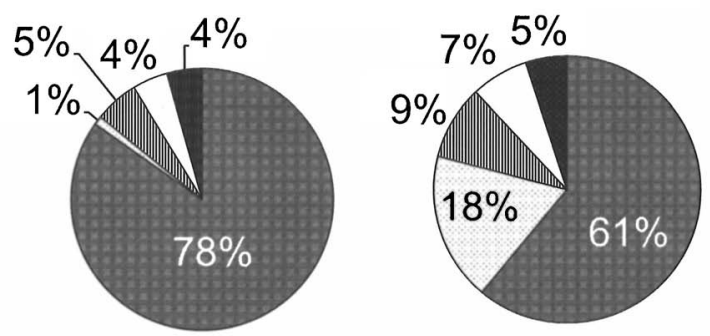

$\square<1.1 \mu \mathrm{m}$

$\square 1.1-2.0 \mu \mathrm{m}$

血 2.0-3.3 $\mu \mathrm{m}$

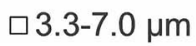

$>7.0 \mu \mathrm{m}$

Fig. 6. Size distributions of airborne particles (A) and PAHs (B) collected in Kyoto. mutagenic potency of ambient air was associated with the concentration of airborne particles in spring, and potent mutagenicities were detected for the samples collected on days when the particle concentrations were high, such as March 16 or 17, 2009. The results of back trajectory analysis indicated that air masses for those days moved from the Asian continent to each sampling site in Japan (Fig. 5). This suggests that airborne particles including Asian dust and mutagens arrived in Japan in March 2009, and long-range transport of mutagens was evident at Yurihama, which has few large emission sources of air pollutants around the sampling site.

Size distributions of airborne particles and $10 \mathrm{PAHs}$, representative air pollutants formed by incomplete combustion of organic matter such as fossil fuels, were examined for airborne particles collected in Kyoto for two periods with and without an Asian dust event. As shown in Fig. 6 , the ratios of large size particles $(>7.0$ and 3.3-7.7 $\mu \mathrm{m}$ ) were high among airborne particles for the period including an Asian dust event, but PAHs were mainly distributed in the smallest size fraction $(<1.1$ $\mu \mathrm{m})$ for both periods. It is reported that the mass concentration of airborne particles during Asian dust event was predominated by coarse particles (29-31), and the result in this study was consistent with these findings. There are some reports on the size distribution of PAHs in airborne particles, and PAHs were mainly detected in 
small size fractions (32-34). These results suggest that a large number of coarse particles were transported as Asian dust and that air pollutants formed from incomplete combustion, such as PAHs, mainly existed among fine particles for periods with and without an Asian dust event. However, there are few reports on the size distribution of mutagens in airborne particles for periods of an Asian dust event. Long-range transport of fine particles, such as $\mathrm{PM}_{2.5}$, has recently been reported (35). Some fine particles are formed by combustion of organic matter such as fossil fuels and reactions of primary gases in ambient air. Further study is necessary to clarify whether air pollutants are attached to fine particles of Asian dust and transported to Japan. In addition, it is important to clarify whether mutagenic/carcinogenic compounds are transported as fine particles emitted from anthropogenic sources with long-range transport by the winter monsoon.

Acknowledgements: This study was supported by the Grants-in-aid for Cancer Research and the Health and Labour Sciences Research Grants, for Research on global health issues, from the Ministry of Health, Labour, and Welfare of Japan and the Environment Research and Technology Development Fund (C-1154) of the Japanese Ministry of the Environment.

Conflicts of interest: The authors do not have any conflicts of interest.

\section{References}

1 Archer VE. Air pollution and fatal lung disease in three Utah counties. Arch Environ Health. 1990; 45: 325-34.

2 Dockery DW, Pope CA III, Xu X, Spengler JD, Ware $\mathrm{JH}$, Fay ME, et al. An association between air pollution and mortality in six U.S. cities. N Engl J Med. 1993; 329: 1753-9.

3 Pope CA III, Thun MJ, Namboodiri MM, Dockery DW, Evans JS, Speizer FE, et al. Particulate air pollution as a predictor of mortality in a prospective study of U.S. adults. Am J Respir Crit Care Med. 1995; 151: 669-74.

4 Pope CA III, Burnett RT, Thun MJ, Calle EE, Krewski $\mathrm{D}$, Ito $\mathrm{K}$, et al. Lung cancer, cardiopulmonary mortality, and long-term exposure to fine particulate air pollution. JAMA-J AM Med Assoc. 2002; 287: 1132-41.

5 Pope CA III, Burnett RT, Thurston GD, Thun MJ, Calle EE, Krewski D, et al. Cardiovascular mortality and longterm exposure to particulate air pollution: epidemiological evidence of general pathophysiological pathways of disease. Circulation. 2004; 109: 71-7.

6 Barbone F, Bovenzi M, Cavalleri F, Stanta G. Air pollution and lung cancer in Trieste, Italy. Am J Epidemiol. 1995; 141: 1161-9.

7 Katanoda K, Sobue T, Satoh H, Tajima K, Suzuki T, Nakatsuka $H$, et al. An association between long-term exposure to ambient air pollution and mortality from lung cancer and respiratory diseases in Japan. J Epidemiol.
2011; 21: 132-43.

8 Höner A, Arnold M, Hüsers N, Kleiböhmer W. Monitoring polycyclic aromatic hydrocarbons in waste gases. J Chromatogr A. 1995; 710: 129-37.

9 Kamiya A, Ose Y. Isolation of dinitropyrene in emission gas from a municipal incinerator and its formation by a photochemical reaction. Sci Total Environ. 1988; 72: 1-9.

10 Henderson TR, Sun JD, Royer RE, Clark CR, Li AP, Harvey TM, et al. Triple-quadrupole mass spectrometry studies of nitroaromatic emissions from different diesel engines. Environ Sci Technol. 1983; 17: 443-9.

11 Handa T, Yamauchi T, Sawai K, Yamamura T, Koseki $\mathrm{Y}$, Ishii $\mathrm{T}$. In situ emission levels of carcinogenic and mutagenic compounds from diesel and gasoline engine vehicles on an expressway. Environ Sci Technol. 1984; 18: 895-902.

12 Katayama M, Ohara T, Murano K. Source-receptor analysis for sulfur compounds in East Asia by a regional transport modeling system coupled with a meteorological model. J Jpn Soc Atmos Environ. 2004; 39: 200-17.

13 Hsu S-H, Liu SC, Jeng W-L, Lin F-J, Huang Y-T, Lung S-CC, Liu T-H, Tu J-Y. Variations of $\mathrm{Cd} / \mathrm{Pb}$ and $\mathrm{Zn} / \mathrm{Pb}$ ratios in Taipei aerosols reflecting long-range transport or local pollution emission. Sci Total Environ. 2005; 347: 111-21.

14 Hioki T, Nakanishi S, Mukai H, Murano K. Analysis of long-range transported and local air pollution with trace metal concentration ratio and lead isotope ratio in precipitation. J Jpn Soc Atmos Environ. 2008; 143: 100-11.

15 Mukai H, Tanaka A, Fujii T. Lead isotope ratios of airborne particulate matter as tracers of long-range transport of air pollutants around Japan. J Geophys Res. 1994; 99: 3717-26.

16 Yang X-Y, Okada Y, Tang N, Matsunaga S, Tamura K, Lin J-M, et al. Long-range transport of polycyclic aromatic hydrocarbons from China to Japan. Atmos Environ. 2007; 41: 2710-8.

17 National Bureau of Statistics of China, Statistical communiqué of the People's Republic of China on the 2009 national economy and social development, Beijing, China, available at: http://www.stats.gov.cn/tjgb/ ndtjgb/qgndtjgb/t20100225_402622945.htm, 2010.

18 Zhao B, Wang SX, Liu H, Xu JY, Fu K, Klimont Z, et al. NOx emissions in China: historical trends and future perspectives, Atmos Chem Phys. 2013; 13: 9869-97.

19 Sekiguchi K. Characteristics of $\mathrm{PM}_{2.5}$, J Jpn Soc Atmos Environ. 2010; 45: A54-60.

20 Hasei T, Watanabe T, Hirayama T. Determination of 3,6-dinitrobenzo[e]pyrene in surface soil and airborne particles by high-performance liquid chromatography with fluorescence detection. J Chromatogr A, 2006; 1135: 65-70.

21 Yahagi T, Nagao M, Seino Y, Matsushima T, Sugimura T. Mutagenicities of $N$-nitrosamines on Salmonella. Mutat Res. 1977; 48: 121-9.

22 Watanabe M, Ishidate M, Nohmi T. Sensitive method for detection of mutagenic nitroarenes and aromatic amines: New derivatives of Salmonella typhimurium tester strains 
possessing elevated $O$-acetyltransferase levels. Mutat Res. 1990; 234: 337-48.

23 Hasei T, Watanabe T, Endo O, Sugita K, Asanoma M, Goto $\mathrm{S}$, et al. Determination of 3,6-dinitrobenzo[e]pyrene in surface soil and airborne particles, and its possible sources, diesel particles and incinerator dusts. J Health Sci. 2009; 55: 567-77.

24 http://www.ready.noaa.gov / hypub-bin / trajtype.pl?run type $=$ archive

25 http://www.data.kishou.go.jp / obs-env / kosahp / kosa_ table_2009.html

26 Kaneyasu N, Takada H. Seasonal variations of sulfate, carbonaceous species (black carbon and polycyclic aromatic hydrocarbons), and trace elements in fine atmospheric aerosols collected at subtropical islands in the East China Sea, J Geophys Res. 2004; 109: D06211.

27 Hioki T, Nakanishi S, Mukai H, Murano K. Analysis of long-range transport of aerosols with water-soluble ionic species and trace metal components, collected continuously with particle size segregation in the coastal area of the Sea of Japan-Focusing on the Kosa Event in spring 2002. J Aerosol Res. 2006; 21: 160-75.

28 Kaneyasu N, Sato K, Takami A, Hidemori T, Matsui Y, Yamamoto S. PM2.5 and particulate substances concerning human health in upwind areas of Japan. Earozoru Kenkyu, 2014; 29: 82-94.

29 Mizohata A, Ito K. Chemical modification of Kosa particles. Earozoru Kenkyu. 1995; 10: 127-34.
30 Mori I, Nishikawa M, Tanimura T, Quan H. Change in size distribution and chemical composition of Kosa (Asian dust) aerosol during long-range transport. Atmos Environ. 2003; 37: 4253-63.

31 Kaneyasu N, Sugimoto N, Shimizu A, Yamamoto S, Kawamoto K. Comparison of lidar-derived dust extinction coefficients and the mass concentrations of surface aerosol. J Jpn Soc Atmos Environ. 2012; 47: 285-91.

32 Kawanaka Y, Matsumoto E, Sakamoto K, Wang, N, Yun S-J. Size distributions of mutagenic compounds and mutagenicity in atmospheric particulate matter collected with a low-pressure cascade impactor. Atmos Environ. 2004; 38: 2125-32.

33 Gutierrez-Daban A, Fernandez-Espinosa, AJ, TernerroRodrigues M, Fernandez-Alvarez F. Particle-size distribution of polycyclic aromatic hydrocarbons in urban air in southern Spain. Anal Bioanal Chem. 2005; 381: 721-36.

34 Ladji R, Yassaa N, Balducci C, Cecinato A. Particle size distribution of n-alkanes and polycyclic aromatic hydrocarbons (PAHS) in urban and industrial aerosol of Algiers, Algeria. Environ Sci Pollut Res. 2014; 21: 1819-32.

35 Kaneyasu N, Takami A, Sato K, Hatakeyama S, Hayashi M, Hara K, et al. Long-range transport of $\mathrm{PM}_{2.5}$ in northern Kyushu area in spring. J Japan Soc Atmos Environ. 2010; 45: 227-34. 